\title{
Large stores and contracting for mall locations
}

\author{
Tarun Sabarwal \\ Department of Economics \\ University of Texas at Austin \\ sabarwal@eco.utexas.edu
}

\author{
Randal Watson* \\ Department of Economics \\ University of Texas at Austin \\ watson@eco.utexas.edu
}

March 21, 2005

Preliminary

\begin{abstract}
We analyze the contracting problem between a shopping mall and potential anchors (large stores) in a market where consumers with high search costs must choose shopping destinations prior to learning prices. Our model incorporates the interaction between contracting and asymmetric firm sizes into a framework of competing platforms. The mall is but one of three potential destinations in the market, complemented by a stand-alone location for a large store, and a competitive 'downtown' centre occupied by small retailers. As in Dudey's (1990) homogeneousgood framework, consumers choose to visit only one of these locations, based on expected prices at each site. A game of sequential contracting for slots at the mall determines the equilibrium distribution of firms across locations based on their costs and relative bargaining power.

We analyze the effects of three policies. First, prohibition of the stand-alone site can increase social welfare, by alleviating excess entry and countering inefficiencies in contracting between the mall owner and potential anchors. Second, subsidies for downtown may push prices at the mall closer to socially efficient levels, but can never increase welfare if the market is initially dominated by a stand-alone big store. A subsidy's effect on the equilibrium size distribution of mall tenants depends on the concavity of demand. Third, a merger between two big stores can increase social welfare, in part by ameliorating a problem of externalities on non-traders in the contracting with the mall owner. Merged anchor stores that operate at stand-alone sites may retain occupancy of mall space for purely strategic reasons, in order to deter entry.
\end{abstract}

\footnotetext{
${ }^{*}$ Corresponding author.
} 


\section{Introduction}

This paper investigates some theoretical aspects of the contracting between the owner of a shopping mall and the large stores which are the mall's potential anchor tenants. We think of a mall as a platform, under single ownership, for the sale of a homogeneous good by both small and large tenants, competing under Cournot conditions. These small and large sellers each have the option of choosing to sell the good at another, competing location. Small sellers can choose to locate in a 'downtown' area, near other small sellers in a district where the available retail premises are under fragmented ownership. A large seller can choose to set up operation outside the mall as a stand-alone, 'big box' store.

As in Dudey (1990), consumers have high search costs and are ex ante uninformed about prices - they choose one of these three locations to visit based on the expected price there. All else equal, this expected price will be lower at locations with more sellers. Competition between the mall and the alternative locations is therefore an instance of platform competition, in which the site that attracts the greatest number of efficient suppliers wins the largest share of customer visits. Our aim in this paper is to highlight the ways in which this platform competition interacts with the contracting problem between the mall owner and the potential anchor stores.

The empirical work of Gould, Pashigian, and Prendergast (2002) reveals that anchor stores in shopping malls typically pay low rentals relative to the amount of space they occupy. Those authors present evidence suggesting that these low rentals reflect the externalities that the anchors generate for a mall's smaller tenants. Consumers prefer to shop at clusters of stores (such as shopping malls) in order to economize on search costs. A large anchor store makes a concomitantly larger contribution to a cluster's overall attractiveness, and can therefore negotiate a lower rental with the mall owner.

In practice both the mall owner and potential anchors each have outside options. Anchors have the option of choosing an 'off-mall' stand-alone site, such as those favored by major discount stores, while the mall owner has the option of negotiating with other potential tenants. These alternatives condition the contracting between mall owner and anchor. At the same time the outside options are mutually interdependent, because it is through these alternative avenues that the mall and potential anchor will interact if they fail to reach a tenancy agreement.

In other words, contracting over mall space is endogenous with the outcomes of platform competition in the market as a whole. Both are jointly 
determined by more fundamental factors such as the relative efficiencies of competing anchor stores, the costs of operating at particular locations, and the ownership structures of competing platforms. To capture these relationships in a tractable framework we employ a stylized model which nevertheless provides some insights into the effects of simple policy experiments. Firms at all three locations - the downtown area, the stand-alone site for a single large store, and the mall - produce the same homogeneous good, and there is no locational differentiation between consumers: the outcome of the platform competition is therefore 'winner takes all', with one location receiving all customers. Bargaining with potential anchors over mall space centres on a fixed-fee rental and a number of other tenants who will be allowed into the mall. We assume that this bargaining with potential tenants happens sequentially, and that it is efficient in the sense that the parties do not 'leave surplus on the table' in any bilateral contracting.

Throughout the paper we are concerned with effects on product markets, which we illustrate by analyzing three policies in particular. First, we examine the effect of restrictions on the alternative locations available to anchors. Instances of such restrictions (whether proposed or actual) may be found in various communities around the United States. For example, the city council in Austin, Texas recently passed a 'Big Box Ordinance' that bars large retail stores (but not small stores) from locating in an environmentally sensitive watershed. ${ }^{1}$ Legislation that similarly targets new construction of very large stores is mooted in other jurisdictions as well. ${ }^{2}$ One common impact of such regulations is to make it relatively harder for large retailers to open new stand-alone locations. We abstract from other details of these measures by considering the extreme example of a policy that bars any large store from locating off-mall.

Our second policy experiment looks at 'downtown revitalization' efforts, which in recent decades have been a topic of interest at all levels of government. In particular we consider the effects of subsidizing the downtown location, i.e., the small stores' alternative to the mall. Government assistance for depressed downtown areas could include, for example, tax incentives for local businesses, financing for infrastructure projects, and seed money for

\footnotetext{
${ }^{1}$ The regulation bars any new retail store with an area in excess of 100,000 square feet from a zone covering a local aquifer. City of Austin Ordinance No. 031204-57, Dec. 2003.

${ }^{2} \mathrm{~A}$ bill introduced in the New Jersey legislature proposes to strengthen oversight of development applications from 'superstore retailers', by subjecting such applications to regional economic impact studies, and allowing appeals against such development by neighbouring municipalities. New Jersey state bill A3504.
} 
urban planning. ${ }^{3}$ For analytical convenience we assume here that the assistance takes the form of a simple subsidy to reduce the fixed costs of entry at the downtown location.

Finally we consider the effects of a merger between two potential anchor stores, one of which may locate in the mall, while the other may locate at the outside stand-alone location. This is a stylization of the pending merger between the Sears department-store chain and K-mart discount stores. The former mainly has its stores in malls, while outlets of the latter are mainly in off-mall locations. Of interest here is the likely effect of this merger on the combined operation's location strategies. One stated aim of the proposal is to expand Sears' presence in off-mall locations. ${ }^{4}$ We use our model to determine the circumstances in which a merged entity maintains outlets both in malls and at free-standing locations, or abandons one type of location entirely to focus on the other.

Equilibria in our stylized market exhibit four possible sources of inefficiency. The welfare effects of each of the policy experiments depend on the manner in which they affect these inefficiencies. First, the number of sellers at the mall may be too small, because of the owner's monopolistic incentive to restrict competition, in order to extract more surplus from customers (via the rents paid by tenants). On the other hand, competition from other locations can lead to too many firms at the mall, because of the problem of business stealing, studied by Mankiw and Whinston (1986), among others. Third, there are externalities on non-traders (Segal 1999) in the contracting between the mall owner and the large stores. The mall owner's threat to contract with another potential anchor can lead to a big store locating in the mall even when the stand-alone location would have been less costly. A final type of inefficiency arises when a high-cost big store can commit to negotiating a mall tenancy before the mall owner talks to another, more efficient potential anchor. If the mall owner has little bargaining power versus the efficient big store then it may lease a slot to the early bargainer, the high-cost tenant, leaving the efficient seller with no customers in equilibrium.

We find that a ban on the stand-alone location can improve social welfare in two ways. It may ameliorate the problem of business-stealing, by supplanting a stand-alone big store with a mall comprised of smaller sellers with

\footnotetext{
${ }^{3}$ See, for example, Pennsylvania DCED (2004), describing that state's Main Streets Program, which funds a variety of activities that foster small business development in traditional downtown locations. Downtown areas could also benefit from inclusion in Enterprise Zones and Tax Increment Financing districts. For recent empirical work on these programs see, e.g., O'Keefe (2004) and Gibson (2003) and the references therein.

${ }^{4}$ See Bhatnagar (2004).
} 
lower fixed costs. Also, by strengthening the bargaining power of the mall owner, it may prevent a less-efficient big store from levering its way into a mall slot via a commitment to first position in the bargaining sequence. On the other hand the ban can reduce social welfare by exacerbating the mall owner's monopolistic rent extraction, or by forcing an efficient big store to relocate from outside into a costly mall location. If the ban does not cause an incumbent big store to exit the market altogether then the latter effect dominates, and the overall welfare change is weakly negative.

Subsidies for the downtown location may reduce or increase social welfare, respectively by exacerbating the excess entry problem, or by countering monopolistic rent extraction by the mall owner. In one significant case the welfare effect is unambiguous - the subsidy reduces welfare when the standalone big store is initially the dominant location (i.e., the location that gets all the customers). This is in contrast to the effects of the location restrictions discussed above: the difference arises because a subsidy for downtown tends to expand entry at the mall, and hence if anything reinforces excess entry. We show also how the effects of the subsidy on the profitability of a mall with an anchor (relative to a mall with no anchor) depend on the concavity of demand.

The effect on social welfare of a merger between two big stores is generally positive. In our model the stores do not merge in order to coordinate prices - our assumptions on consumer behaviour ensure that such coordination is not possible. Instead they may merge in order to influence the outcomes of contracting with the mall owner. There are two principal effects on this contracting. First, the merger removes the possibility that the less-efficient big store may, by virtue of a commitment to bargaining first, force an outcome in which it gets all the customers. Second, the merger counters the problem of externalities on non-traders, in part by admitting a new type of contract in which an efficient stand-alone big store maintains a slot in the mall for a less-efficient sister store. This arrangement allows the mall owner to share (via the rental contract) in some of the profit gains from siting the efficient big store at the least-cost outside location. If these profit gains are large enough the merger may benefit not just the big stores, but also the mall owner.

Studies of anchor stores and the externalities they provide in shopping malls are fairly sparse in the literature. Gould, Pashigian, and Prendergast (2002) and Pashigian and Gould (1998) estimate the externalities using data on rental contracts for tenants in a sample of large shopping malls. Theoretical explanations for the observed differences in rentals between anchors 
and non-anchors are provided. ${ }^{5}$ Konishi and Sandfort (2003) ask why malls contain anchors in the first place. They model anchors as providing a standardized product with price known in advance to all consumers. This guarantees a minimum level of utility for any potential mall shopper, who may be less certain about the qualities and prices of goods at non-anchor stores. The anchor's presence in a mall effectively alleviates the costs of consumer search, simultaneously drawing consumers from a wider area and attracting other stores to the same location.

In contrast to these papers we model a shopping mall as only one of a number of potential locations in a market, endogenizing stores' choices between locations. This permits the study of policy experiments which affect these locations differentially. More generally our paper is related to the fastgrowing literature on two-sided markets, in particular those studies which deal with competition between platforms. A very incomplete list of theoretical papers with competing two-sided markets includes Rochet and Tirole (2003), Armstrong (2004) and Gehrig (1998). ${ }^{6}$ Unlike our work, papers in this literature have devoted little attention to the issue of asymmetric sizes of platform members. Here we focus on these asymmetries, analyzing their interaction with the competition between three possible platforms. ${ }^{7}$ Insofar as each platform has a different ownership structure, our work is also related to Nocke, Peitz and Stahl (2004), who study the effects of different ownership structures on a single isolated platform. ${ }^{8}$

The next section explains the basic structure of the model, and discusses some of the assumptions underlying the framework. Section 3 characterizes the equilibrium distribution of firms across locations in terms of the profit functions and the bargaining sequence, and also discusses social welfare in these equilibria. The first of our policy experiments, a ban on stand-alone locations, is analyzed in section 4 . Section 5 considers the effects of subsidizing the downtown area, while section 6 looks at a merger between two big stores. Section 7 concludes. Most of the proofs of the propositions and lemmas are contained in the appendix.

\footnotetext{
${ }^{5}$ Other empirical work on shopping malls may be found in West (1992). Basker (2005) has estimated the effect on local markets of entry by a Walmart store.

${ }^{6}$ Useful further references may be found in Armstrong (2004), for example.

${ }^{7}$ Rochet and Tirole (2003, Proposition 5) briefly mention the effects of 'marquee buyers' in their model of competing platforms.

${ }^{8}$ Another distinction between our work and some papers in this literature (e.g., Rochet and Tirole (2003), Armstrong (2004)) is that we focus on situations where there is competition between sellers on the same platform.
} 


\section{$2 \quad$ Model}

Consider the following model, a variation on the framework of Dudey (1990). There are $T$ identical consumers in a market for a homogeneous product: each consumer has a well-behaved inverse demand of $p(q)$ for the good. Without loss of generality normalize $T=1$. The good can be produced at big stores and small stores. There are two big stores, called $B 1$ and $B 2$, and a countably infinite number of small stores. Both the big and small stores produce the same homogeneous product, the former with respective constant marginal costs of $b_{1}$ and $b_{2}$, and the latter with constant marginal cost of $c$. Assume that $b_{2}<b_{1}<c$, so that $B 1$ and $B 2$ are 'big' in the sense of having lower marginal costs of production, and $B 2$ is the 'larger' of the two.

There are three potential locations in the market: $A$ (for 'stand alone'), $D$ (for 'downtown'), and $L$ (for 'mall'). The downtown location $D$ can only be occupied by small stores. It is a competitive rental market with a countably infinite number of potential landlords, who each have a capital cost $K_{D}$ of leasing their premises to a tenant shopkeeper. With many potential tenants on the demand side this $K_{D}$ then becomes the fixed competitive rental rate in the downtown area.

The stand-alone location $A$ can only be occupied by one of the big stores $B i, i=1,2$. If $B i$ locates at $A$ it faces a fixed cost $G_{i}, i=1,2$, representing the capital cost of constructing a store.

The mall location can be occupied by one or zero big stores and any finite number of small sellers. Stores that locate at the mall pay a rental to a mall anchor (or 'developer'), called $E$. Rentals for space in the mall are determined through a process of bargaining between $E$ and the prospective tenants. The mall owner faces capital costs $K_{B i}$ of providing a space for a big store $i$ and $K_{S}$ of providing a space for a small store. We assume $K_{B i} \geq K_{S}, i=1,2$.

These ownership structures are a stylization based on observed outcomes in real-world retail markets. At the $D$ location the dispersed ownership reflects the nature of downtown areas in most American towns and cities, where the available retail spaces are held by many different landlords. The set of potential tenants of these spaces includes not just retail stores but also many businesses of other types, so the assumption of a competitive rental market seems a reasonable approximation. Our exclusion of big stores from the downtown area is based on observation of small to medium-sized markets (population 25,000 - 175,000, say), where large general-merchandise stores almost always prefer stand-alone or mall locations near the edge of town. 
Obviously large department stores may be found in the downtown areas of larger cities, where access to public transport may compensate for the lack of car parking space. In future work we plan to address this issue by examining subsidies for department stores to locate in downtown districts.

Store locations are determined by a game in which the mall owner first bargains sequentially with the big stores over the terms under which either of them might locate in the mall. We will consider both possible sequences for bargaining between $E$ and the big stores: $B 2$ then $B 1$, and vice versa. After bargaining with the big stores, $E$ then offers a number of additional slots in the mall (which could be zero) to the small stores. Big stores which decline to join the mall then choose whether or not to locate at $A$, in the order $B 2$ then $B 1$. Finally the remaining small stores choose whether or not to locate at $D$. There is perfect information in this process in the sense that all potential entrants are immediately and fully informed about the outcome of each stage of the contracting process.

The competition between stores after locations have been chosen follows Dudey (1990). Consumers ex ante observe the configuration of stores at each location, including the number of sellers and their respective types (i.e., whether $B 1, B 2$, or small). To learn the prices charged at a location they must visit that place, thereby incurring a search cost. Search costs are sufficiently high that they can only visit one location. Consumers face the same cost of visiting any location. Therefore they visit the location with the lowest expected price, given the distribution of firms there. Firms at each location compete as Cournot oligopolists, taking as given the number of consumers who visit that site. There is no spatial differentiation among consumers: therefore in equilibrium all consumers will end up shopping at the same location (if there are no ties); that is, only one location ends up getting any customers. ${ }^{9}$

Let $\pi_{S 0}(N)$ denote variable profits per customer of a small firm with costs $c$ in an $N$-firm symmetric Cournot equilibrium at any given location. Let $p_{0}(N)$ be the price in such a symmetric equilibrium. Let $\pi_{B i}(N)$ and $\pi_{S i}(N)$, for $i=1,2$, respectively denote variable profits per customer of firms with costs $b_{i}$ and $c$, in an asymmetric Cournot equilibrium with one lowcost firm $B i$ and $N$ high-cost firms. Therefore $\pi_{B i}(0)$ would be the variable profits per customer of a firm $B i$ with $\operatorname{costs} b_{i}$ operating as a monopoly at

\footnotetext{
${ }^{9}$ To be a little more specific about the post-entry order of moves, assume that after consumers choose shopping destinations on the basis of observed configurations of stores, sellers at each location learn these choices (i.e., they see how many consumers showed up at their location), and then engage in quantity-setting Cournot competition. See Dudey (1990) for further details.
} 
a particular location. Let $p_{i}(N), i=1,2$, be the price in an asymmetric Cournot equilibrium with one low-cost firm with costs $b_{i}$ and $N$ high-cost firms. ${ }^{10}$

Contracting between $E$ and a big store $B i$ over terms on which the store joins the mall centres on a pair $(r, M)$, where $r$ is a fixed fee $B i$ will pay $E$ as a rental. The variable $M$ is a 'plan', representing the number of slots for small stores that will be built in the mall if $B i$ agrees to join. The order of moves during and after this contracting process is as follows:

- Stage 1. $E$ bargains with one of the big stores $B i$ over a pair $(r, M)$. If agreement is reached then go to Stage 4 .

- Stage 2. Conditional on agreement not being reached in Stage 1, E bargains with $B j, j \neq i$, over an $(r, M)$. If agreement is reached go to Stage 4.

- Stage 3. Conditional on agreement not being reached in Stage 2 (meaning that the mall will have no anchor), $E$ commits to a number $M$ of slots for small stores. (If $E$ decides not to enter the market then he sets $M=0$.)

- Stage 4. E sequentially makes take-it-or-leave-it rental offers to potential tenants for each of the $M$ slots for small sellers fixed in stages 1-3. Each potential entrant receiving an offer decides whether or not to accept it. All agents observe the number of small stores who accept.

- Stage 5. The big store or stores which did not locate in the mall choose (in the order $B 2$ then $B 1$ ) whether or not to locate at $A$. (Only one may locate at $A$.) All agents observe the outcome.

- Stage 6. The remaining small stores sequentially choose whether or not to locate at $D$, at the competitive rental rate $K_{D}$.

The equilibrium concept is subgame perfect Nash. All agents are assumed to receive a reservation payoff of zero if they decline to enter into any contract or join any location.

A central feature of the contracting over mall locations concerns the extent to which the mall owner can commit ex ante to a fixed number of slots in the mall. Here we assume that the commitment occurs at the same time

\footnotetext{
${ }^{10}$ Note that if $T$ were not normalized to 1 , the quantities $p_{i}(N), \pi_{S i}(N), i=0,1,2$, and $\pi_{B i}(N), i=1,2$, would all be independent of $T$, the total number of consumers in the market.
} 
that a contract is signed with an anchor store. This is a convenient starting point for the analysis, which is probably not too far from reality. Gould, Pashigian and Prendergast (2002), for example, suggest that developers typically sign anchor stores early in the tenant-search process in order to obtain lower-cost financing for the mall. Commitment at other stages - e.g., prior to negotiation with any big store - may lead to different results and would be an interesting avenue for future research. For example it might be possible for a mall owner to use an initial commitment to a particular number of small stores in order to improve its bargaining position relative to potential anchor stores.

We assume that the mall owner $E$ has all the bargaining power versus small sellers, to whom he makes take-it-or-leave-it rental offers. After stage 3 of the contracting process he will be committed to a given number $M$ of spaces for small sellers. The marginal cost of letting each of these spaces will be zero, and it will thus be optimal for $E$ to let all $M$ planned spaces. Knowing this, the maximum willingness-to-pay of any potential small tenant would be the small-firm variable profits in Cournot equilibrium with $M$ small firms and 0 or 1 anchors (depending on the outcome of $E$ 's negotiations with $B 1$ and $B 2$ ). Hence this Cournot profit level $\pi_{S i}(M)$ will be the rental offered by $E$ to each small seller. This rental will be accepted by $M$ tenants as long as $M$ is large enough (i.e., $p_{i}(M)$ is low enough) to attract all consumers.

In reality $E$ may be able to set output-dependent rentals, rather than the fixed-fee rentals assumed here. For example, Gould, Pashigian, and Prendergast (2002) report that revenue-based 'overage' percentages are commonly observed in rental contracts for shopping mall space. The literature on vertical contracting would suggest that similar results to the following could be derived in a model which allowed $E$ to use such non-linear tariffs. Thinking of the mall owner as the upstream firm offering non-linear tariff schedules to downstream mall tenants, we could get Cournot outcomes in the final goods market using standard assumptions of secret rental contracts and passive beliefs (see, e.g., Rey and Tirole (1996)). ${ }^{11}$

The assumption that location $A$ cannot have any small stores may not be as restrictive as it might seem. Essentially the distinction between $A$ and $L$ is one of ownership - at the former ownership of the retail premises and the retail brands are unified; at the latter they are separate. The separation in ownership at $L$ makes it credible that the price consumers find there will

\footnotetext{
${ }^{11} \mathrm{~A}$ formalization of this idea is left for future work. It should be noted that some aspects of the present context do not appear in standard vertical contracting models, e.g., here the contracting with the big store involves not just a rental but also a number of small stores.
} 
be the Cournot price and not the higher collusive price. Say for example that $B 2$ locates at $A$ and decides to construct some small-store spaces there in order to give the appearance of greater competition. As always, after these extra spaces are built and tenanted consumers observe the number of sellers at each location and then decide where to shop, with no observation of prices. Suppose that consumers are aware that $B 2$ owns all the retail space at $A$, and suppose that $B 2$ is able to use non-linear quantity-based tariffs in letting space to small sellers. Then $B 2$ will be able to enforce collusive pricing by all sellers at $A$ through its rental contracts, and consumers will realize that such rental contracts would in fact be ex post optimal for $B 2$. As long as consumers do not observe the exact nature of the rental contracts at $A$ they will expect to find the monopoly price $p_{2}(0)$ if they shop at $A$. In that case it will not be optimal for $B 2$ to construct any extra retail spaces. ${ }^{12}$

Let $\Omega=\{0\} \cup[1,+\infty)$. For ease of analysis, it is assumed that if $Z$ represents a number of firms at any location, then $Z \in \Omega$. That is, we respect the $0-1$ integer constraint and ignore the integer restriction for larger numbers. In other words, we restrict the number of big stores at any location to be 0 or 1 , but allow fractional numbers of small firms. ${ }^{13}$ At locations with one big store the number of small stores can be any $N \in[0,+\infty)$; at locations with no big store, $N \in[1, \infty) .{ }^{14}$ Given this simplification, we can define $\pi_{S i}(0), i=1,2$, as $\lim _{N \rightarrow 0} \pi_{S i}(N)$.

Assumption 1 For all $N>0, \pi_{S i}(N)>0$, for $i=1,2$.

That is, any number of small firms can make non-zero variable profits in asymmetric Cournot. This is equivalent to assuming that $c$ is not too high relative to $b_{2}$, e.g., if per-consumer demand is $p(q)=1-q$ then the assumption holds if and only if $1+b_{2}>2 c$.

\footnotetext{
${ }^{12}$ Casual observation suggests that stores such as Walmart may be aware of this kind of credibility problem, since in locating away from malls they usually seem to construct a single stand-alone store, rather than building their own 'mini-mall'. Prentice and Sibly (1996) discuss the advantages to a firm disguising its ownership of multiple retail outlets in the same market.

${ }^{13}$ Dudey (1990) maintains the integer restriction throughout. He derives restrictions on the profit functions under which his basic results are consistent with the inherently discrete location decisions of integer numbers of firms. (See for example his conditions (5) and (13).) Such considerations are not an issue here, where the number of potential small entrants is assumed to be infinite, and the number of potential locations for these entrants is fixed at two.

${ }^{14}$ For example, if $p(q)=1-q$ then $\pi_{S 0}(N) \equiv(1-c)^{2} /(N+1)^{2}$. When $N \in\{1,2,3 \ldots\}$ this gives the usual expressions for Cournot profits in monopoly, duopoly, triopoly, etc.
} 
Assumption 2 Let $\bar{q}$ be the $q$ such that $p(q)=0$. Then

$$
\forall\left(q, q_{-i}\right) \text { s.t. } q+q_{-i} \leq \bar{q}, \quad q p^{\prime \prime}\left(q+q_{-i}\right)+p^{\prime}\left(q+q_{-i}\right)<0 .
$$

This assumption implies that firms' quantities are strategic substitutes: see Tirole (1987, p. 219). It is satisfied by linear demand functions, for example. Note that (1) implies strict concavity of each firm's Cournot profit function.

For brevity it will be useful to continue to use the indices $j=0,1,2$ to refer to situations where there are respectively no low-cost anchors, one lowcost anchor with costs $b_{1}$, and one low-cost anchor with costs $b_{2}$. Then write $V_{j}(N), j=0,1,2$ for the total variable profits of all firms under Cournot competition with $N$ small firms. That is,

$$
\begin{aligned}
& V_{2}(N)=\pi_{B 2}(N)+N \pi_{S 2}(N), N \geq 0 \\
& V_{1}(N)=\pi_{B 1}(N)+N \pi_{S 1}(N), N \geq 0 \\
& V_{0}(N)=N \pi_{S 0}(N), N \geq 1 .
\end{aligned}
$$

Note that $V_{j}(N)$ is continuous (given our admission of non-integer $N$ ), and decreasing in $N \geq 0$, for $j=1,2$, and in $N \geq 1$ for $j=0$.

Let $L_{0}$ (respectively, $L_{1}, L_{2}$ ) represent a mall with no anchor (respectively an anchor $B 1$, an anchor $B 2$ ). Let $A_{i}$ represent $A$ occupied by big store $B i$. For notational convenience let $A_{0}$ represent the stand-alone location with no occupant. Define a configuration $k(N)$ to be a location $k \in\left\{D, L_{0}, L_{1}, L_{2}, A_{1}, A_{2}\right\}$ and a number of small sellers $N$ at that location. Let $\Gamma(k(N))$ denote the joint profits (of landlords and tenants), net of fixed costs, of any configuration $k(N)$ when that configuration is the only one permitted to operate in the market. Thus

$$
\begin{aligned}
\Gamma(D(N)) & =V_{0}(N)-N K_{D}, N \geq 1 \\
\Gamma\left(L_{0}(N)\right) & =V_{0}(N)-N K_{S}, N \geq 1 \\
\Gamma\left(L_{i}(N)\right) & =V_{i}(N)-K_{B i}-N K_{S}, N \geq 0, i=1,2 \\
\Gamma\left(A_{i}(0)\right) & =V_{i}(0)-G_{i}, i=1,2 .
\end{aligned}
$$

Note that $\Gamma\left(A_{i}(N)\right)$ is not defined for $N>0$, or for $i=0$.

We say that a configuration is feasible if its potential variable profits cover its fixed costs, i.e., if $\Gamma(k(N)) \geq 0$.

\section{Assumption 3 a. $V_{0}(1)>K_{D}$}
b. $V_{0}(1)>K_{S}$
c. $V_{i}(0)>K_{B i}$ for $i=1,2$ 


\section{d. $V_{i}(0)>G_{i}$ for $i=1,2$}

This assumption implies that the configurations $D(1), L_{0}(1), L_{i}(0)$ and $A_{i}(0), i=1,2$ are all feasible. Note that feasibility alone does not mean that in equilibrium a given configuration will end up attracting any customers.

In the sequel it turns out that the relative attractiveness of the locations $D$ and $A_{2}$ is central to the analysis. Let $N_{D}$ be the number of small firms that arises with free entry at $D$, if that is the only location permitted. That is, $V_{0}\left(N_{D}\right) \equiv N_{D} K_{D}$. We have $N_{D}>1$ by virtue of the preceding assumption. (Dependence of $N_{D}$ on $K_{D}$ will usually be left implicit.) The location that gets all the consumers in equilibrium will be called the active location. Note that if $A_{2}$ is the active location the price there must always be $p_{2}(0)$. We will say that ' $D$ beats $A_{2}$ ' (or $D \succ A_{2}$ ) if there is a feasible downtown configuration with a price $p_{0}(N)$ that is lower than $p_{2}(0)$. Equivalently we can state the definition as follows:

Definition 1 We say $D \succ A_{2}$ if there exists $N$ such that $p_{0}(N)<p_{2}(0)$ and $V_{0}(N) \geq N K_{D}$. If there is no such $N$ we say that $A_{2} \succ D$.

By analogy we can extend this definition to cover comparisons between $D$ and mall configurations. For example we will say $D \succ L_{2}(M)$ if there exists $N$ such that $p_{0}(N)<p_{2}(M)$ and $D(N)$ is feasible. Note that there will be no need to extend the definition to cover $A_{1}$ because under certain assumptions that location will never be active in equilibrium.

In what follows attention will focus on how many small firms are needed at the mall in order to reduce the Cournot price there below the price at one of the competing locations $A$ and $D$. This number will depend on whether or not there is a big store at the mall. In general let $M_{0}, M_{1}$, and $M_{2}$ respectively define minimum such numbers of small firms at $L_{0}, L_{1}$, and $L_{2}$. Add to these indicators the extra subscript $A$ or $D$ to indicate whether the reference alternative location is $A_{2}$ or $D$. Thus $M_{0 A}$, for example, is the smallest $M$ needed to get the price at $L_{0}(M)$ below the price at $A_{2}$. That is, $p_{0}\left(M_{0 A}\right) \equiv p_{2}(0)$. Similarly $M_{1 D}$ (respectively $\left.M_{2 D}\right)$ is the minimum number of small stores needed at $L_{1}$ (respectively $L_{2}$ ) in order to get the asymmetric Cournot equilibrium price there down to the price at the downtown district when $D$ has $N_{D}$ sellers. (The dependence of $M_{1 D}$ (or $M_{2 D}$ ) on $K_{D}$ will usually be left implicit.) That is, $p_{1}\left(M_{1 D}\right) \equiv p_{2}\left(M_{2 D}\right) \equiv p_{0}\left(N_{D}\right)$. Finally, define $M_{1 A}$ to be such that $p_{1}\left(M_{1 A}\right)=p_{2}(0)$ : the price at $L_{1}\left(M_{1 A}\right)$ is equal to the price at $A_{2}(0){ }^{15}$

\footnotetext{
${ }^{15}$ Note that there is no need to define an $M_{0 D}$ : this is by definition equal to $N_{D}$, since
} 
Assumption 4 For all $K_{D}>0$, the potential net profits $\Gamma\left(L_{i}(N)\right)$ of mall configurations $L_{i}(N), i=1,2$, are such that

$$
\Gamma\left(L_{1}\left(M_{1 A}\right)\right)<\Gamma\left(L_{2}(0)\right) \text { and } \Gamma\left(L_{1}\left(M_{1 D}\right)\right)<\Gamma\left(L_{2}\left(M_{2 D}\right)\right) .
$$

This assumption simply means that the most efficient way (in terms of the joint profits of tenants and the developer) for a mall to reach the price $p_{0}\left(N_{D}\right)$, or $p_{2}(0)$, is with the big store $B 2$ rather than $B 1$. The assumption always holds if, for example, $B 1$ has higher fixed costs at the mall than $B 2$ (i.e., if $K_{B 1} \geq K_{B 2}$ ). It will also hold for some $K_{B 1}<K_{B 2}$. The assumption is used merely to simplify the discussion; in particular, it restricts the number of cases in which $L_{1}$ will be an outcome.

In order to break ties between locations it will be assumed that when the expected prices at two alternative shopping destinations are equal, all consumers observe the following order of precedence: $A$ is preferred over $L, L$ is preferred over $D$. Further assume that if a big store is indifferent between locating at $A$ and accepting a contract for a mall slot, then it chooses $A$. And if the developer is indifferent between contracts for two different mall configurations, then it chooses $L_{2}$ over $L_{1}$, and $L_{1}$ over $L_{0}$.

\section{Analysis}

\subsection{Introduction}

We do not explicitly model the determination of $r$ in the bargaining over $(r, M)$ between $E$ and each big store $B i$. Rather, we simply assume that $E$ negotiates with the big stores sequentially, and that the bilateral contracting at each stage maximizes the joint surplus of the two parties. That is, let $\Delta_{i}^{j}$ be the payoffs of agent $j \in\{E, B i\}$ in the subgame following a stage where $E$ and $B i$ have failed to reach agreement on a contract. Then $S_{i}$, the maximum achievable joint surplus arising from agreement between the two parties on $(r, M)$, is defined as

$$
S_{i}(M) \equiv \Gamma\left(L_{i}(M)\right)-\left(\Delta_{i}^{E}+\Delta_{i}^{B i}\right), i=1,2, M \geq 0 .
$$

The actual surplus from agreement only attains this maximum if $M$ is large enough to win all consumers in equilibrium. Let $M_{i}^{*}$ be the smallest $M$ such that configuration $L_{i}(M)$ wins all the customers in an equilibrium of the subgame following agreement on $M$. (Note that $S_{i}(M)$ is decreasing in $M \geq M_{i}^{*}$.) And let $S_{i}^{*} \equiv S_{i}\left(M_{i}^{*}\right)$.

small firms have the same marginal costs whether they are at $L$ or $D$. 
Assumption 5 When $E$ and Bi negotiate they reach agreement on $M_{i}^{*} \geq 0$ if and only if $S_{i}^{*} \geq 0, i=1,2$. Otherwise they reach no agreement.

Implicit in this assumption is the notion that if $S_{i}\left(M_{i}^{*}\right) \geq 0$ then the rental $r$ can be set so as to make both $E$ and $B i$ weakly prefer agreement over disagreement. Let $\theta_{i} \in[0,1]$ denote the share of surplus that $E$ expects to get from bargaining with $B i, i=1,2$. In the policy analysis to follow we will hold these shares to be exogenously fixed.

As the game of location choices is one of complete and perfect information it has a unique subgame-perfect Nash equilibrium, which is easily found by backward induction. To solve for this equilibrium what matters is the non-mall location which constitutes the strongest competition for the mall. Thus if, for example, $A_{2}$ beats $D$, then $A_{2}$ would be the strongest outside location, and this is the option that constrains the contracting over mall configurations. The existence of $D$ then becomes in a sense irrelevant, as it cannot be the active location if the mall negotiations break down. The opposite is true if $D$ beats $A_{2}$ : then it cannot be optimal for $B 2$ to choose $A$, because at best its price there would exceed the price in the free-entry downtown configuration $D\left(N_{D}\right)$.

To see this in more detail, consider the subgames ensuing from Stage 3 of the contracting process, i.e., after the determination of a configuration for the mall (including the possibility of the 'null configuration', $L_{0}(0)$, meaning no entry at the mall). Note first that $B 1$ never enters at $A$ in an equilibrium of any of these subgames. For if it were profitable for $B 1$ to locate at $A$, then a fortiori it would be profitable for $B 2$ to pre-empt this by locating there first.

Second, among these subgames consider those in which $B 2$ declined to join the mall (i.e., subgames ensuing from $L_{i}(M), i \neq 2$ ). If $D \succ A_{2}$ then $B 2$ never enters the market in an equilibrium in any of these subgames. For if $B 2$ chose $A$ and won any customers then a fortiori it would have been optimal for $N_{D}$ small firms to locate at $D$ (since $p_{0}\left(N_{D}\right)<p_{2}(0)$ and $D\left(N_{D}\right)$ is feasible). Furthermore, although ownership of slots at $D$ is dispersed, the combination of subgame perfection and sequential entry eliminates the possibility of any failure to coordinate on $D\left(N_{D}\right)$ there: the equilibrium outcome will thus be $D\left(N_{D}\right)$ if and only if $D$ beats $A_{2}$ and $D$ beats $L_{i}(M)$. Alternatively, if $A_{2} \succ D$ the outcome in an equilibrium of any of these subgames can only be $A_{2}$ or $L_{i}(M)$, depending on which of these configurations yields the lowest price, $p_{2}(0)$ or $p_{i}(M)$.

Subsequent analysis of the whole game is divided into two cases, according to whether $E$ negotiates first with $B 1$ or $B 2$. From the preceding 
comments it follows that $B 1$ 's disagreement payoff in these negotiations is always zero. For $B 2$ the disagreement payoff could be zero, if $D \succ A_{2}$, or positive, if $A_{2} \succ D$ and $E$ has no feasible alternative configuration which yields a lower price than $p_{2}(0)$. Hence each of the above two cases is further divided into two subcases: ' $A_{2}$ beats $D$ ', and ' $D$ beats $A_{2}$ '.

\subsection{Case 1: $E$ bargains with $B 2$ then $B 1$}

Assume firstly that $A_{2}$ beats $D$. In this case if $E$ disagrees with $B 2$ then his subsequent ability to capture the market is constrained by the need to beat $A_{2}$ on price. If

$$
\max \left\{\Gamma\left(L_{1}\left(M_{1 A}\right)\right), \Gamma\left(L_{0}\left(M_{0 A}\right)\right)\right\}<0
$$

then $E$ cannot form a feasible configuration which will beat $A_{2}$.

Proposition 1 a. If (3) holds then the equilibrium outcome is $A_{2}$, or $L_{2}(0)$, as $G_{2}$ is $\leq$, or $>, K_{B 2}$.

b. If (3) does not hold then the outcome is $L_{2}(0)$ or $L_{0}\left(M_{0 A}\right)$ depending on which is the greater of $\Gamma\left(L_{2}(0)\right)$ and $\Gamma\left(L_{0}\left(M_{0 A}\right)\right)$.

Intuitively, the proposition states that if (3) holds then $B 2$ has the "upper hand' in negotiations with $E$, and the outcome will be $A_{2}$ or $L_{2}(0)$, depending on the relative fixed costs of establishing these configurations. If (3) does not hold then $E$ holds the upper hand, and a mall outcome will result, with a configuration (either $L_{2}(0)$ or $L_{0}\left(M_{0 A}\right)$ ) that maximizes the net joint profits of $E$ and his tenants.

Note that $B 1$ is not active in any of the equilibrium outcomes. This is a consequence of Assumption 4. However the presence of $B 1$ is not irrelevant because the threat that he might agree with $E$ on $L_{1}\left(M_{1 A}\right)$ limits $B 2$ 's freedom to choose $A_{2}$ (see (3)). Furthermore the bargaining outcome does not always maximize the joint payoffs of $E$ and his tenants. In particular if $G_{2}<K_{B 2}$ and if, for example, $\Gamma\left(L_{2}(0)\right)>\Gamma\left(L_{0}\left(M_{0 A}\right)\right)>0$ then the outcome is $L_{2}(0)$, even though $A_{2}$ would have yielded a greater sum of variable profits minus fixed costs for all actual and potential parties to the contracting. The presence of this inefficiency represents an instance of 'externalities on non-traders', as studied in, e.g., Segal (1999). Here the externality would be imposed on $B 2$ by $E$ 's subsequent contracting with $B 1$ and/or the small firms. In the sequel it will be seen that the welfare effects of some policies depend in part on how they affect this inefficiency. ${ }^{16}$

\footnotetext{
${ }^{16}$ Note however that our framework does not fall into the general class of problems on which Segal focuses. In particular, the payoffs and trades do not satisfy his 'Condition
} 
We now briefly cover the case of ' $D$ beats $A_{2}$ '. If

$$
\max \left\{\Gamma\left(L_{2}\left(M_{2 D}\right)\right), \Gamma\left(L_{0}\left(N_{D}\right)\right)\right\}<0
$$

then $E$ cannot form any configuration which will beat $D$ and the outcome will thus be $D$. If (4) does not hold then the outcome is $L_{2}\left(M_{2 D}\right)$ or $L_{0}\left(N_{D}\right)$, depending on which is the greater of $\Gamma\left(L_{2}\left(M_{2 D}\right)\right)$ and $\Gamma\left(L_{0}\left(N_{D}\right)\right)$. Note that in this case there are no externalities on non-traders and the outcome maximizes the joint net profits of $E$ and its actual and potential tenants (subject to the constraint that any agreed mall configuration has to beat $D$, i.e., it must yield a price no greater than $p_{0}\left(N_{D}\right)$.)

\subsection{Case 2: $E$ bargains with $B 1$ then $B 2$}

Assume firstly that $A_{2}$ beats $D$.

Proposition 2 a. If (3) holds then the equilibrium outcome is $A_{2}$, or $L_{2}(0)$, as $G_{2}$ is $\leq$, or $>, K_{B 2}$.

b. If (3) does not hold and $\Gamma\left(L_{1}\left(M_{1 A}\right)\right)<\Gamma\left(L_{0}\left(M_{0 A}\right)\right)$ then the outcome is $L_{2}(0)$ or $L_{0}\left(M_{0 A}\right)$, depending on which is the greater of $\Gamma\left(L_{2}(0)\right)$ and $\Gamma\left(L_{0}\left(M_{0 A}\right)\right)$.

c. If (3) does not hold and $\Gamma\left(L_{1}\left(M_{1 A}\right)\right) \geq \Gamma\left(L_{0}\left(M_{0 A}\right)\right)$ then the outcome is $L_{1}\left(M_{1 A}\right)$ or $L_{2}(0)$, depending on whether $S_{1}^{*}$ is positive or negative, where

$$
S_{1}^{*}=\Gamma\left(L_{1}\left(M_{1 A}\right)\right)-\left[\max \left(0, \Gamma\left(L_{0}\left(M_{0 A}\right)\right)\right)+\theta_{2} \max \left[0, S_{2}^{*}\right]\right]
$$

and

$$
\begin{aligned}
S_{2}^{*} & =G_{2}-K_{B 2} \quad \text { if } \Gamma\left(L_{0}\left(M_{0 A}\right)\right)<0 \\
& =\Gamma\left(L_{2}(0)\right)-\Gamma\left(L_{0}\left(M_{0 A}\right)\right) \quad \text { if } \Gamma\left(L_{0}\left(M_{0 A}\right)\right)>0 .
\end{aligned}
$$

The difference between this proposition and the situation of first bargaining with $B 2$ lies in part (c), where the outcome $L_{1}$ now becomes possible. By Assumption 4 the joint net profits from the configuration $L_{2}(0)$ always exceed those from $L_{1}\left(M_{1 A}\right)$. However $E$ 's disagreement payoff in bargaining with $B 1$ is determined not by the absolute level of $L_{2}(0)$, but by his share of the joint surplus $S_{2}^{*}$. This share could be small relative to what $E$ gets

W'. This is because in the present problem outcomes depend in part on the identity of the non-traders. 
from agreement with $B 1$, either because $S_{2}^{*}$ is small, or because $\theta_{2}$ is small, or both.

One interesting case that falls under part (c) is when $\theta_{2}=1, \Gamma\left(L_{1}\left(M_{1 A}\right)\right)>$ $0>\Gamma\left(L_{0}\left(M_{0 A}\right)\right)$ and $G_{2}<K_{B 2}$. These parameter values in Proposition 1 would have led to agreement on $L_{2}(0)$ in the bargaining with $B 2$, because of $E$ 's threat to contract with $B 1$. This threat is no longer available when $E$ bargains with $B 2$ second, rather than first. Then bargaining with $B 2$ would result in disagreement, with $B 2$ choosing $A_{2}$. As a result $E$ prefers to pre-empt this situation by concluding an agreement with $B 1$. That is, as can be seen from $(5), S_{1}^{*}=\Gamma\left(L_{1}\left(M_{1 A}\right)\right)>0$.

Negotiation with $B 1$ before $B 2$ introduces a second source of inefficiency into the contracting outcomes. The previous sub-section discussed a problem of externalities on non-traders, whereby contracting could lead to the outcome $L_{2}(0)$, even when $G_{2}<K_{B 2}$, which implies inefficiency in the sense that $\Gamma\left(L_{2}(0)\right)<\Gamma\left(A_{2}(0)\right)$. Note however that the outcome $L_{2}(0)$ is still the configuration which yields the highest net profits of all feasible mall configurations. If $E$ and $B 1$ agree on $L_{1}$ (as may occur in part (c) of Proposition 2) then the contracting outcome is not even efficient in that limited sense. That is, by Assumption 4, the agreed mall configuration $L_{1}\left(M_{1 A}\right)$ yields strictly lower net profits than another feasible mall configuration $L_{2}(0)$, which yields the same price $p_{2}(0)$. Furthermore if $G_{2}<K_{B 2}$ (as in the example discussed in the previous paragraph) then this type of inefficiency may co-exist with the externalities-on-non-traders problem, because the outcome $L_{2}(0)$ itself yields lower joint net profits than $A_{2}$.

It can be seen that this second type of inefficiency relies on $B 1$ 's ability to commit to bargaining with $E$ only once, prior to negotiation with $B 2$. If $E$ had the option of re-entering talks with $B 1$ after disagreement with $B 2$ then the outcomes would be as in proposition 1, with no possibility of $L_{1}$ occurring. Note however that it is in B1's interests to commit to bargaining once and once only, before $E$ meets $B 2$, because $B 1$ gets zero payoff otherwise. Thus the relevance of Proposition 2(c) depends on the extent to which one believes that $B 1$ has ways of making such a commitment. Although we do not explicitly model these commitment methods here, they might perhaps arise in a more general model in which $B 1$ could threaten to negotiate with rival malls.

We now briefly consider the case of $D$ beats $A_{2}$. If $\Gamma\left(L_{1}\left(M_{1 D}\right)\right)<$ $\Gamma\left(L_{0}\left(N_{D}\right)\right)$ then $L_{1}\left(M_{1 D}\right)$ is the least profitable of the three mall configurations that match the price at $D\left(N_{D}\right)$, and the outcomes for this case will be the same as those discussed for the corresponding cases (for ' $D$ beats $A_{2}$ ') in the previous subsection. On the other hand, if $\Gamma\left(L_{1}\left(M_{1 D}\right)\right)>\Gamma\left(L_{0}\left(N_{D}\right)\right)$ 
then the outcome will be $L_{1}\left(M_{1 D}\right)$ or $L_{2}\left(M_{2 D}\right)$, depending (in part) on how much surplus $E$ expects to get from bargaining with $B 2$. The precise expression for $S_{1}^{*}$ in this case is similar to (5):

$$
S_{1}^{*}=\Gamma\left(L_{1}\left(M_{1 D}\right)\right)-\left[\max \left(0, \Gamma\left(L_{0}\left(N_{D}\right)\right)\right)+\theta_{2} \max \left(0, S_{2}^{*}\right)\right]
$$

where

$$
S_{2}^{*}=\min \left[\Gamma\left(L_{2}\left(M_{2 D}\right)\right), \Gamma\left(L_{2}\left(M_{2 D}\right)\right)-\Gamma\left(L_{0}\left(N_{D}\right)\right)\right] .
$$

When the outcome is $L_{1}\left(M_{1 D}\right)$ (as when $\theta_{2}=0$, for example) we have an inefficiency in the sense that another outcome $\left(\Gamma\left(L_{2}\left(M_{2 D}\right)\right)\right)$ could have raised the joint profits of the mall and its tenants, while still matching the price $p_{0}\left(N_{D}\right)$.

\subsection{Welfare expressions in Cournot equilibrium}

The preceding analysis introduced two possible sources of social inefficiency in the contracting over mall locations: externalities on non-traders, and inefficient allocation of commitment power. In the discussion to follow two further sources of social inefficiency will emerge. First, it will be seen that the mall owner has an incentive to restrict competition at the mall in order to (indirectly) extract surplus from consumers. On the other hand when the mall is forced to compete with the other locations, a tendency toward excess entry may emerge, because of business-stealing effects. Incentives of the latter kind have been extensively studied in, e.g., Mankiw and Whinston (1986).

It is useful to develop in advance some simple welfare expressions which capture the tradeoff between these two additional effects. Consider then Cournot competition at location $L_{2}$, between one big store $B 2$ and $M>0$ small firms, assuming that this is the only location permitted in the market. For brevity let $p(M)$ denote the Cournot equilibrium price in this configuration $L_{2}(M)$. Social welfare in this equilibrium may be written as:

$$
W=\int_{p(M)}^{\infty} q(u) \cdot d u+\pi_{B 2}(M)+M \pi_{S 2}(M)-K_{B 2}-M K_{S},
$$

where $q($.$) represents the consumer's demand function.$

Lemma 1 In Cournot equilibrium at $L_{2}(M)$, where $M>0$,

a. if $K_{S}=0$ and the competition is symmetric (i.e., the big and small stores have the same marginal costs), then $d W / d M>0$; 
b. if $\pi_{S 2}(M) \leq K_{S}, d W / d M<0$.

Part (a) of the lemma is intuitively obvious: adding firms to the location moves price closer to marginal cost, and therefore raises welfare if fixed costs are zero and if the new firms have the same variable costs as all existing firms. Part (b) is related to the excess entry result given (for symmetric firms) in Proposition 1 of Mankiw and Whinston (1986). It says that there are too many firms at the location if the last small firm added only broke even, or failed to cover its fixed costs.

The following result will also be of use in related contexts:

Lemma 2 If $N$, a number of small firms in symmetric Cournot competition, and $M$, a number of small firms in asymmetric Cournot competition with the big store B2, are such that $p_{2}(M)=p_{0}(N)$, then $\pi_{S 2}(M)=\pi_{S 0}(N)$.

This lemma says that the per-firm variable profits of small firms are the same in symmetric and asymmetric Cournot configurations if the equilibrium prices are the same in each configuration. The proof follows from observation of the small firms' FONC in Cournot equilibrium.

\section{Banning the stand-alone location}

We examine here a policy that bans the stand-alone location $A$, reducing the market to just the mall $L$ and the downtown area $D$. Note firstly that, regardless of the order of bargaining between $E$ and the big stores, the ban would have no effect in cases where $D$ beats $A_{2}$. This is because the existence of the location $A$ does not condition the contracting outcomes in those cases. That is, in those cases no player's disagreement payoff is affected by the elimination of $A$.

Take then cases where $A_{2}$ beats $D$, and suppose firstly that $E$ bargains with $B 2$ then $B 1$. Recall (from Proposition 1) that without the ban the possible outcomes were $A_{2}, L_{2}(0)$, and $L_{0}\left(M_{0 A}\right)$. It can be seen (by similar reasoning to that used in Proposition 1$)$ that after the ban is introduced the outcome will be one of the mall configurations $L_{2}(0)$ and $L_{0}\left(N_{D}\right)$, depending on which is the greatest of $\Gamma\left(L_{2}(0)\right)$ and $\Gamma\left(L_{0}\left(N_{D}\right)\right)$. The downtown location $D$ is not an equilibrium outcome, since the policy does not prevent $B 2$ from relocating into the mall. That is, $E$ always has the option of contracting with $B 2$ on the configuration $L_{2}(0)$, which beats $D$. Thus the policy does not actually benefit the downtown location.

If the equilibrium outcome before the policy was a no-anchor mall $L_{0}\left(M_{0 A}\right)$, then after the ban the outcome must still be a no-anchor mall, $L_{0}\left(N_{D}\right)$, with 
just enough small tenants to induce a price $p_{0}\left(N_{D}\right)$ equal to the lowest feasible price at $D$. This is because a necessary condition for a pre-policy outcome of $L_{0}\left(M_{0 A}\right)$ is that this configuration yield higher net profits than the anchor mall $L_{2}(0)$ (i.e., $\left.\Gamma\left(L_{0}\left(M_{0 A}\right)\right)>\Gamma\left(L_{2}(0)\right)\right)$. Since $A_{2}$ beats $D$ we must have $N_{D}<M_{0 A}$, implying that $\Gamma\left(L_{0}\left(N_{D}\right)\right)>\Gamma\left(L_{2}(0)\right)$, i.e., the no-anchor mall is still the net-profit maximizing configuration after the ban.

Since the mall owner extracts all rents from no-anchor malls, it follows that E's payoff strictly increases in this case. The ban's effects on social welfare $W$ are however ambiguous. To see this write social welfare in configuration $L_{0}\left(M_{0 A}\right)$ as:

$$
W=\int_{p_{0}\left(M_{0 A}\right)}^{\infty} q(u) \cdot d u+M_{0 A} \pi_{S 0}\left(M_{0 A}\right)-M_{0 A} K_{S},
$$

and note that this corresponds to (6) with $b_{2}=c, K_{B 2}=K_{S}, M_{0 A}=M+1$. It then follows from Lemma 1 (a) that if $K_{S} \approx 0$ social welfare will be lower at $L_{0}\left(N_{D}\right)$ than at $L_{0}\left(M_{0 A}\right)$. That is, with no fixed costs the policy causes social welfare to fall, because the elimination of competition from $A_{2}$ allows $E$ to restrict entry to the mall in order to extract more surplus from consumers (via its rental contracts).

Suppose on the other hand that in the configuration $L_{0}\left(M_{0 A}\right)$ the small firms are generating close to zero net profits, i.e., $M_{0 A} K_{S} \approx V_{0}\left(M_{0 A}\right)$. Then $M_{0 A}$ is effectively the 'free-entry' number of small firms for the $L_{0}$ configuration. (That is, it represents the amount of entry that would occur if $L_{0}$ were the only permitted configuration and if the per-store rental were to be exogenously set to $K_{S}$.) This number is consistent with equilibrium as long as $K_{B 2}$ is such that $\Gamma\left(L_{2}(0)\right)$ is also small, i.e., such that $\Gamma\left(L_{0}\left(M_{0 A}\right)\right)>\Gamma\left(L_{2}(0)\right)>0$. It then follows from Lemma $1(\mathrm{~b})$ that a move from $M_{0 A}$ to a slightly lower number $N_{D}$ (as would be induced by a ban on $A$ when $K_{D}$ is slightly higher than $K_{S}$ ) would strictly increase social welfare. The policy leads to an improvement in social welfare by countering the excess entry induced by business-stealing effects. Note that in this case the original excess entry at $L_{0}\left(M_{0 A}\right)$ is in effect forced onto the mall owner by the threat of competition from $A_{2}$.

Now consider cases where the active equilibrium location before the policy was the anchor mall $L_{2}(0)$ or the stand-alone big store $A_{2}$. It is then easy to construct examples where the effect of the ban is to switch the outcome from $L_{2}(0)$ or $A_{2}$ to the no-anchor mall $L_{0}\left(N_{D}\right)$. The mall owner gains from such a switch. (His pre-policy payoff was no greater than $\Gamma\left(L_{2}(0)\right.$ ), which is less than $\Gamma\left(L_{0}\left(N_{D}\right)\right)$ when $L_{0}\left(N_{D}\right)$ is the post-policy outcome.) 
And $B 2$ clearly loses. Furthermore it is also possible to construct examples to show that social welfare may again rise or fall with the switch in outcome. ${ }^{17}$ A rise means relatively large benefits from the amelioration of business-stealing effects. A fall reflects the dominance of two negative effects: the first is the monopolistic entry-restriction effect mentioned earlier; the second is a variable-cost effect, representing the switch from the low-cost producer $B 2$ to the high-cost small stores.

When the introduction of the policy does not cause the big store to exit the market (i.e., when $A_{2}$ or $L_{2}(0)$ before the ban becomes $L_{2}(0)$ after the ban) the welfare implications are more clearcut. The ban in this case has no effect on price, which is the same $p_{2}(0)$ before and after, and therefore no effect on output, consumer surplus, or variable profits. If the pre-policy outcome was $A_{2}$ then fixed costs will rise, from $G_{2}$ to $K_{B 2}$. (Note from Proposition 1 that the $A_{2}$ outcome requires $G_{2}<K_{B 2}$.) Otherwise fixed costs are unchanged, and so social welfare will overall weakly decrease. Payoffs to the big store decrease, because of the weakening of its disagreement payoff, and also because the joint net profits of the equilibrium outcome will decrease when $B 2$ is forced into the mall (i.e., when $A_{2}$ is switched to $\left.L_{2}(0)\right)$. On the other hand the mall owner's payoffs increase, because the mall is now always active, and because his disagreement payoff increases. ${ }^{18}$

Overall effects of the ban on $A$ are summarized as follows:

Proposition 3 If $A_{2}$ beats $D$ and the bargaining is with B2 first, a ban on the stand-alone location:

a. weakly raises price and reduces consumer welfare;

b. raises the mall owner's profits;

c. reduces $B 2$ 's profits, and reduces the set of cases in which this big store is part of the equilibrium outcome;

d. does not benefit the downtown location;

\footnotetext{
${ }^{17}$ To see a welfare increase as the equilibrium outcome switches from $A_{2}$ to $L_{0}\left(N_{D}\right)$, set $p(q)=1-q, b_{2}=0, G_{2}=K_{B 2}=0.25, c=0.4, K_{S}=0.11, K_{D}=0.04$. To see a welfare decrease for the same switch, change $c$ to $0.045, K_{S}$ to $0.003, K_{D}$ to 0.0625 .

${ }^{18}$ To see the rise in $E$ 's payoff, briefly consider possible cases in turn. If $A_{2}$ is switched to $L_{2}(0), E$ gets positive payoff instead of 0 . If $L_{2}(0) \rightarrow L_{2}(0)$ and $\max \left(\Gamma\left(L_{1}\left(M_{1 A}\right)\right), \Gamma\left(L_{0}\left(M_{0 A}\right)\right)\right)<0$, then $E$ 's disagreement payoff was no greater than 0 beforehand, whereas now it is at least 0 , and joint net profits are unchanged. If $L_{2}(0) \rightarrow L_{2}(0)$ and $\max \left(\Gamma\left(L_{1}\left(M_{1 A}\right)\right), \Gamma\left(L_{0}\left(M_{0 A}\right)\right)\right)>0$ then joint net profits are unchanged, B2's disagreement payoff is zero before and after, while $E$ 's disagreement payoff rises from $\max \left(\Gamma\left(L_{1}\left(M_{1 A}\right)\right), \Gamma\left(L_{0}\left(M_{0 A}\right)\right)\right)$ to $\max \left(\Gamma\left(L_{1}\left(M_{1 D}\right)\right), \Gamma\left(L_{0}\left(N_{D}\right)\right)\right)$.
} 
e. weakly reduces social welfare if the big store remains in the market; and otherwise may increase or reduce social welfare.

Turn now to the effect of the ban in the case where the bargaining is with $B 1$ first. Recall from Proposition 2 (a) and (b) that if $\Gamma\left(L_{1}\left(M_{1 A}\right)\right)<$ $\max \left(\Gamma\left(L_{0}\left(M_{0 A}\right)\right), 0\right)$ (as, for example, when $K_{B 1}$ is relatively high) then the outcomes in this case will be the same as when $B 2$ is the first to bargain. It follows that all of the effects on overall welfare observed in the preceding Proposition may also be observed here. In particular the effect of the ban on social welfare could be positive or negative. To fix ideas let us therefore assume that fixed costs are the same for all stores outside downtown, i.e.,

$$
G_{2}=K_{B 2}=K_{B 1}=K_{S}
$$

In this case the welfare effect of the ban on $A$ would definitely be nonpositive under the conditions of the preceding proposition. ${ }^{19}$ We will show that when $B 1$ bargains first this is not necessarily the case; the policy may increase social welfare, through its effect on the disagreement payoffs of $E$ and $B 2$.

In addition to (8) suppose for illustrative purposes that

$$
\Gamma\left(L_{1}\left(M_{1 A}\right)\right)>0>\Gamma\left(L_{0}\left(M_{0 A}\right)\right) \text {, and } \Gamma\left(L_{0}\left(N_{D}\right)\right)>0 .
$$

Furthermore let $\theta_{2}$, the mall owner's share of $S_{2}^{*}$, be equal to one and let $G_{2}=K_{B 2}+\epsilon$, where $\epsilon$ is small and positive. Prior to the ban, if $E$ disagrees with $B 1$ the surplus from agreement with $B 2$ would then be

$$
S_{2}^{*}=G_{2}-K_{B 2} \geq 0 .
$$

Since $\Gamma\left(L_{0}\left(M_{0 A}\right)\right)<0$, E's disagreement payoff in bargaining with $B 2$ is $\Delta_{2}^{E}=0$. (And $\Delta_{2}^{B 2}=V_{2}(0)-G_{2}$; hence we get the preceding expression for $S_{2}^{*}$.) The surplus from bargaining between $B 1$ and $E$ is therefore

$$
S_{1}^{*}=\Gamma\left(L_{1}\left(M_{1 A}\right)\right)-\theta_{2} S_{2}^{*} .
$$

For $\epsilon$ sufficiently small we have $S_{2}^{*} \approx 0$ and so $S_{1}^{*}>0$, implying that $E$ and $B 1$ agree on the configuration $L_{1}\left(M_{1 A}\right)$. Payoffs of $\theta_{2} S_{2}^{*}+\theta_{1}\left(\Gamma\left(L_{1}\left(M_{1 A}\right)\right)-\right.$ $\left.\theta_{2} S_{2}^{*}\right) \approx \theta_{1} \Gamma\left(L_{1}\left(M_{1 A}\right)\right)$, and $\left(1-\theta_{1}\right) \Gamma\left(L_{1}\left(M_{1 A}\right)\right)$ go to $E$ and $B 1$, respectively.

\footnotetext{
${ }^{19}$ To see this note that (8) implies $\Gamma\left(L_{2}(0)\right)>\Gamma\left(L_{0}\left(N_{D}\right)\right.$ ) (because $K_{B 2} \leq N_{D} K_{S}$, and $\left.V_{2}(0)>V_{0}\left(N_{D}\right)\right)$. Hence the outcome after the ban will be $L_{2}(0)$, implying a weak welfare reduction by part (e) of the proposition.
} 
Now suppose that $A$ is banned. Then the mall owner only needs to beat $D$ in his contracting with the big stores, and $E$ 's disagreement payoff if the bargaining reaches $B 2$ would be $\Gamma\left(L_{0}\left(N_{D}\right)\right)$. Thus

$$
S_{2}^{*}=\Gamma\left(L_{2}(0)\right)-\Gamma\left(L_{0}\left(N_{D}\right)\right)>0,
$$

and $E$ 's payoff from the bargaining with $B 2$ would be

$$
\Gamma\left(L_{0}\left(N_{D}\right)\right)+\theta_{2} S_{2}^{*}=\Gamma\left(L_{2}(0)\right) .
$$

In the bargaining with $B 1$ the surplus is thus

$$
S_{2}^{*}=\Gamma\left(L_{1}\left(M_{1 D}\right)\right)-\Gamma\left(L_{2}(0)\right)<0 .
$$

Hence the mall owner does not reach agreement with $B 1$, contracting instead with $B 2$ on $L_{2}(0)$ and realizing a payoff of $\Gamma\left(L_{2}(0)\right)$, which is strictly greater than its prior payoff of $\theta_{1} \Gamma\left(L_{1}\left(M_{1 A}\right)\right)$.

As a result of the policy we see:

- no change in price; hence no change in consumer welfare;

- lower fixed costs (compare $K_{B 1}+M_{1 A} K_{S}$ before with $K_{B 2}$ after);

- lower total variable costs (because of B2's lower marginal cost of production).

Thus social welfare increases.

Proposition 4 If $A_{2}$ beats $D$ and the bargaining is with $B 1$ first, then a ban on the stand-alone location

a. can increase social welfare in cases where it would reduce welfare if $B 2$ bargains first; and

b. increases social welfare if it leads to the mall replacing a less-efficient anchor with $B 2$.

The point of the proposition is to show that certain kinds of inefficiency in the contracting between the mall and its large tenants introduce policy effects entirely separate from, and potentially opposite to, the effects of business stealing and of monopolistic rent extraction. These inefficiencies manifest themselves in equilibrium mall configurations that do not maximize joint profits over all mall configurations. Restrictions on locations counter these inefficiencies by altering retailers' bargaining positions versus the mall 
owner, potentially leading to the appearance of 'super malls', tenanted by the most efficient big stores. When observed, policy-induced switches to these super-mall configurations are necessarily welfare improving.

An interesting outstanding question concerns whether in a more general model the ban on stand-alone locations, by inducing a switch to a more efficient mall configuration, might lead to a strictly lower equilibrium price. Price reductions are not observed in the present context because of the stylized winner-takes-all nature of the competition. In a model with differentiation between locations we could have multiple active locations in equilibrium. It then seems at least intuitively plausible that if, for example, downtown and the mall are the active locations, then the advent of a more efficient mall anchor might lead to a lower equilibrium price. We plan to investigate this issue in future work.

\section{Subsidizing the downtown location}

Suppose that any firm locating at $D$ receives a lump-sum subsidy of amount $t$. Thus the effective rental rate at the downtown location becomes $K_{D}-t$. The subsidy is only paid if downtown is the active location in equilibrium. If $A_{2}$ beats $D$ (strictly) then small levels of subsidy will have no effect on equilibrium outcomes, since the outside option that constrains the bargaining over mall locations will still be $A_{2}$. Consider then the effect of small subsidies when $D$ beats $A_{2}$. We will later take up the case of $A_{2} \succ D$, considering levels of $t$ that are large enough to reverse $A_{2}$ 's dominance over D.

For simplicity we will assume in this section that the bargaining is with $B 2$ first. Recall from section 3 that in this case with $D \succ A_{2}$ there are three possible equilibrium outcomes: $D, L_{2}\left(M_{2 D}\right)$, and $L_{0}\left(N_{D}\right)$. When $D$ is the equilibrium outcome it is easy to see that introducing a subsidy must reduce social welfare. This follows from, for example, the analysis of Mankiw and Whinston (1986) referred to earlier. That is, when $D$ is the active location the number of firms there, $N_{D}$, will be the free-entry number, which in the present context will be socially excessive. Subsidizing entry at $D$ merely exacerbates this inefficiency.

When the equilibrium outcome is $L_{0}\left(N_{D}\right)$ or $L_{2}\left(M_{2 D}\right)$ a subsidy at $D$ can improve or reduce social welfare. Again this can be seen by applying Lemma 1. Take for example the case of the no-anchor mall $L_{0}\left(N_{D}\right)$. Let $N_{D}(t)$ represent the 'free-entry' number of small firms at $D$ with a subsidy of $t$, i.e., $N_{D}(t)$ is such that $V_{0}\left(N_{D}(t)\right)=N_{D}(t)\left(K_{D}-t\right)$. Thus the effect 
on the mall of a small subsidy $t>0$ can be understood as a small increase in $N_{D}$, the number of small firms at $L_{0}$. As in (7), write social welfare in outcome $L_{0}\left(N_{D}\right)$ as: ${ }^{20}$

$$
W=\int_{p_{0}\left(N_{D}\right)}^{\infty} q(u) \cdot d u+N_{D} \pi_{S 0}\left(N_{D}\right)-N_{D} K_{S} .
$$

Whether $W$ rises or falls with the subsidy depends on the relative strengths of two countervailing effects: excess entry through business stealing, and monopolistic rent extraction. If $K_{S} \approx 0$ then $d W / d N_{D}>0$, from Lemma 1 (a): the subsidy raises welfare by pushing market outcomes closer to marginal cost pricing. But if $\pi_{S 0}\left(N_{D}\right) \approx K_{S}$ then $d W / d N_{D}<0$, from Lemma 1 (b): the subsidy reduces welfare by exacerbating the excess entry effects of business stealing. ${ }^{21}$ Thus when the mall is the initial equilibrium outcome the welfare effects of a downtown subsidy are ambiguous.

Turn now to the case of $A_{2} \succeq D$. To show that there are cases where the welfare effects of a subsidy are not ambiguous, examine in particular the case where the initial equilibrium outcome is the stand-alone big store $A_{2}$. Since small subsidies for $D$ have no effect when $A_{2} \succ D$, we are considering here levels of subsidy large enough to reverse this ordering, so that the subsidized downtown location beats $A_{2}$, i.e., $D(t) \succ A_{2}$. It emerges that in this case subsidies can only reduce social welfare.

Proposition 5 If $B 2$ bargains first, subsidizing the downtown location when the equilibrium outcome is $A_{2}$ weakly reduces social welfare.

To see the intuition of the proposition, note firstly that if the stand-alone big store $A_{2}$ was the initial equilibrium then the configuration $L_{0}\left(M_{0 A}\right)$ cannot have been feasible. Furthermore if the no-anchor mall was not feasible before the subsidy nor can it be feasible after the subsidy, since $N_{D}(t)$, the number of small firms required to beat the subsidized downtown location, must be greater than $M_{0 A}$. Hence the equilibrium after the subsidy must yield either the downtown or the anchor-mall outcome. If the former, the number of small firms at $D, N_{D}(t)$, will exceed the 'free-entry' number $N_{D}(t=0)$, and a decline in welfare then follows from the excess-entry results of Mankiw and Whinston. The core of the proof is then to show that a similar type of excess-entry result will hold even if the post-subsidy outcome was the anchor mall $L_{2}\left(M_{2 D}(t)\right)$.

\footnotetext{
${ }^{20}$ Note that there is no term for the cost of the subsidy in this expression, because the subsidy is not paid unless $D$ is the active location.

${ }^{21}$ Note that $\pi_{S 0}\left(N_{D}\right) \equiv K_{D}$ by definition, so that this case of a negative welfare effect is likely when $K_{S}$ is only slightly less than $K_{D}$.
} 
The result of this proposition stands in contrast to Proposition 3, where it was seen that banning the stand-alone location when $A_{2}$ is the equilibrium outcome can in some circumstances increase social welfare. In that case the welfare increase arises because the ban counters the business-stealing effects of a big store's entry at $A$. That is, the ban may result in the equilibrium outcome changing to a no-anchor mall $L_{0}\left(N_{D}\right)$. If this change does not increase prices too much, and if the small stores at $L_{0}\left(N_{D}\right)$ have relatively low fixed costs, the net effect may be an increase in welfare.

Note however that the ban on $A$ does not affect $N_{D}$, the number of small firms required at $L_{0}$ to match the lowest feasible downtown price. And this number $N_{D}$ is strictly less than $M_{0 A}$, the number of small firms required at $L_{0}$ to match the price at $A_{2}$. Hence $L_{0}\left(N_{D}\right)$ can be feasible even when $L_{0}\left(M_{0 A}\right)$ is not. In the case of a subsidy this is no longer true, because the subsidy changes the number of firms $L_{0}$ needs to match the lowest feasible downtown price. This number of firms $N_{D}(t)$ will in fact exceed $M_{0 A}$; hence if $L_{0}\left(M_{0 A}\right)$ is not feasible then nor is $L_{0}\left(N_{D}(t)\right)$. As a result a subsidy cannot transform the equilibrium outcome from $A_{2}$ to $L_{0}$ and the positive benefits of a reduction in business stealing are no longer available.

We saw in Proposition 3 that a ban on $A$ reduced the set of cases for which the big store $B 2$ was active in the market. When $A_{2} \succ D$ and $A$ is banned the equilibrium outcome is always a mall configuration: it was further shown that in some cases the effect of the ban was to convert an anchor mall $L_{2}$ into a no-anchor mall. Since the opposite switch is never observed, the set of parameters for which $B 2$ is active after the ban must be a proper subset of the set of parameters for which $B 2$ is active before the ban.

We now look for a similar result in the case of the subsidy policy. Once again the central question is how the subsidy affects the relative desirability of anchor malls versus no-anchor malls. To show that the set of cases in which $B 2$ is active is strictly smaller under a subsidy we need to show that the subsidy can switch an anchor mall $L_{2}$ to a no-anchor mall $L_{0}$, but not vice versa. (It is trivial, although tedious, to show that in no other case can the subsidy lead to a big-store configuration (i.e., $L_{2}$ or $A_{2}$ ) replacing a configuration with no big store (i.e., $L_{0}$ or $D$ ).)

It turns out that the effect of a subsidy of $t>0$ on the net profits from $L_{2}$ relative to those from $L_{0}$ depends on the concavity of demand. To see this take the case of $D \succ A_{2}$ (since small levels of subsidy have no effect on anything if $\left.A_{2} \succ D\right)$, and suppose that $\max \left(\Gamma\left(L_{2}\left(M_{2 D}\right)\right), \Gamma\left(L_{0}\left(N_{D}\right)\right)\right)>0$. Recall from section 3 that the equilibrium market outcome in this case is then $L_{2}\left(M_{2 D}\right)$ (respectively $\left.L_{0}\left(N_{D}\right)\right)$ as $\Gamma\left(L_{2}\left(M_{2 D}\right)\right)>($ respectively $<$ ) 
$\Gamma\left(L_{0}\left(N_{D}\right)\right)$. Thus whether the outcome is an anchor or a no-anchor configuration depends on the value of

$Y \equiv \Gamma\left(L_{2}\left(M_{2 D}\right)\right)-\Gamma\left(L_{0}\left(N_{D}\right)\right)=V_{2}\left(M_{2 D}\right)-K_{B 2}-M_{2 D} K_{S}-\left[V_{0}\left(N_{D}\right)-N_{D}\left(K_{S}\right)\right]$.

When $Y$ is positive the equilibrium will be $L_{2}$, and vice versa. The subsidy to downtown may be thought of as a reduction in $K_{D}$, so that if $d Y / d K_{D}>0$ then the subsidy can only switch $L_{2}$ to $L_{0}$, never $L_{0}$ to $L_{2}$. We may focus on the case of $K_{S} \leq K_{D}$, since if $K_{S}>K_{D}$ then $\Gamma\left(L_{0}\left(N_{D}\right)\right)<0$, and so $L_{0}$ cannot have been the equilibrium outcome before the subsidy.

Lemma 3 If inverse demand $p(q)$ is weakly concave at all $q$ such that $p(q)>$ 0 , and if $K_{S} \leq K_{D}$ then $d Y / d K_{D} \geq 0$. The inequality is strict if there is strict concavity, or if $K_{S}<K_{D}$.

To see the intuition of the proof, note the following relationship between the concavity of demand and the quantity responses of large and small tenants. Let $q_{B 2}$ (respectively, $q_{S 2}$ ) be the output of a big store (respectively, a small store) in asymmetric Cournot equilibrium under the configuration $L_{2}\left(M_{2 D}\right)$. It can be shown that $d q_{B 2} / d K_{D}>d q_{S 2} / d K_{D}$ if and only if $p^{\prime \prime}(q)<0$, where $q$ is the aggregate quantity produced in equilibrium. Thus if demand is concave, the big store in $L_{2}$ responds to a subsidy for downtown (a reduction in $K_{D}$ ) by reducing its output by more than each small firm. ${ }^{22}$ This means a larger reduction in the variable profits contributed by the big store (relative to the reduction in contribution from each small store). Since the big store's fixed costs are unchanged at $K_{B 2}$, the configuration $L_{2}$ overall becomes less attractive for the mall owner relative to $L_{0}$, the configuration with no big store.

As a consequence of Lemma 3 we have the following result.

Proposition 6 If $B 2$ bargains first and if inverse demand $p(q)$ is weakly concave for all $q$ such that $p(q)>0$, then any subsidy of $t>0$ for the downtown area

a. reduces the set of cases in which $B 2$ is active in equilibrium;

b. weakly reduces the payoffs to the big store B2.

If demand is convex the effects of the subsidy on $B 2$ 's payoffs are ambiguous. In particular, with convex demand it is possible that $d Y / d K_{D}$ in Lemma 3

\footnotetext{
${ }^{22}$ Note that $d q / d K_{D}>0$ for both big and small stores under Assumption 2. That is, per-firm output increases when there are fewer rival firms at the same location.
} 
may be negative, suggesting that a subsidy to $D$ could lead the mall owner to lean more towards configurations with an anchor store. That is, a subsidy might induce a switch in equilibrium outcome from $L_{0}$ to $L_{2}$, in which case $B 2$ would get a positive payoff instead of zero. The payoffs to the mall owner are ambiguous whether or not demand is concave. He will benefit from the subsidy if, for example, it forces the big store to shift into the mall from the stand-alone location (i.e., if it switches $A_{2}$ to $L_{2}\left(M_{2 D}\right)$ ). And of course he loses from the subsidy if it replaces a mall configuration with the downtown area as the active location.

\section{A merger between $B 1$ and $B 2$}

Consider the effects of a merger between the two big stores, so that $B 1$ and $B 2$ are owned by a single company $B$. As stores they remain technologically distinct, and still may not operate at the same location. The order of moves in the game is the same as previously, except the mall owner $E$ now negotiates with $B 1$ and $B 2$ as a single entity. An agreed contract between $E$ and $B$ still specifies a rental and a number of small tenants for the mall. In addition the contract can condition these quantities on the locations of $B 1$ and $B 2$, that is, on which store enters at the mall, and on whether the other store then locates at $A$. We assume that no contractual commitments eventuate if $B$ decides not to locate either $B 1$ or $B 2$ at the mall.

Given our assumptions on consumers' information and search costs, we may ignore incentives for price coordination between the two big stores. This is because consumers only learn prices upon visiting a store, and find search so costly that they never switch locations. Varying the price at $B 1$, for example, cannot have any effect on sales at $B 2$. Hence the price charged by any big store will still be the Cournot equilibrium price for that location, given the number of sellers there and their marginal costs of production. The benefits to ownership of multiple big stores arise in this model not from the ability to coordinate prices, but from the impact joint ownership has on contracting with the mall owner.

There are four ways in which the company $B$ can distribute its stores $B 1$ and $B 2$ between $A$ and $L$, given that the stand-alone location may be left vacant if desired. However two of these are redundant. It cannot be optimal for $B$ and the mall owner $E$ to agree on ' $B 1$ at $L$ (with $N$ small tenants), $B 2$ does not enter the market'. Under Assumption 4 the joint net profits from this configuration would be strictly improved by replacing $B 1$ at the mall

with its more efficient sister store. Similarly it cannot be optimal to agree 
on ' $B 2$ at $L$ (with $N$ small tenants), $B 1$ at $A$ '. If this arrangement were an equilibrium outcome all customers would go to $L$ (regardless of the value of $N$ ), in which case the costs incurred in setting up $B 1$ at $A$ are wasted. Joint net profits would be strictly improved by leaving $B 1$ out of the market altogether.

Contracting over big-store locations therefore focuses on two possible regimes: ' $B 2$ at $L, B 1$ does not enter', and ' $B 2$ at $A, B 1$ at $L$ ', which we abbreviate as $\left(A_{0}, L_{2}\right)$ and $\left(A_{2}, L_{1}\right)$ where necessary. Given that all customers end up going to the same location, it may seem redundant to have two big stores in the market at once. However we will see that the second regime may sometimes emerge as an equilibrium outcome. The installation of $B 1$ at the mall in such cases is a device for $B$ to preclude entry there by any small stores, thus ensuring that all consumers patronize the other big store at the stand-alone location $A$. Within this second regime we can further rule out agreement on ' $B 2$ at $A, B 1$ at $L$ with $N$ small tenants', where $N>0$. For if all consumers were to go to $L$ in this regime, the contracting parties could under Assumption 4 improve their joint profits by replacing $B 1$ at the mall with $B 2$. And if no consumers go to $L$ then joint profits can be increased by setting $N=0$ (thereby avoiding the costs of installing any small mall tenants).

In summary, we may without loss of generality restrict the set of possible contracts between $B$ and $E$ to those that condition on the regime $\left(A_{2}, L_{1}(0)\right)$, or the regime $\left(A_{0}, L_{2}\left(M_{2 D}\right)\right)$, where $M_{2 D}$ may be zero. Consider then the case of $A_{2} \succ D$.

Proposition 7 Suppose that the two big stores merge, and that $A_{2} \succ D$.

a. If $\Gamma\left(L_{0}\left(M_{0 A}\right)\right) \leq 0$ then the equilibrium outcome is $\left(A_{0}, L_{2}(0)\right)$, or $A_{2}$, as $G_{2}>$, or $<, K_{B 2}$.

b. If $\Gamma\left(L_{0}\left(M_{0 A}\right)\right)>0$ then the equilibrium outcome will be $\left(A_{0}, L_{2}(0)\right)$, $\left(A_{2}, L_{1}(0)\right)$, or $L_{0}\left(M_{0 A}\right)$, respectively, depending on which of these configurations provides the greatest joint profits for $E$ and $B$, that is, depending on which is the greatest of:

- $V_{2}(0)-K_{B 2}$

- $V_{2}(0)-G_{2}-K_{B 1}$

- $V_{0}\left(M_{0 A}\right)-M_{0 A} K_{S}$

As in Proposition 1, the distinction between cases (a) and (b) again revolves around who has the 'upper hand' in the contracting between $B$ and $E$. If 
$\Gamma\left(L_{0}\left(M_{0 A}\right)\right) \leq 0$ then $E$ cannot beat $A_{2}$ with a no-anchor mall configuration in the event of disagreement. Then the active equilibrium location must include $B$ 's best store $B 2$ - whether this location is $L$ or $A$ just depends on which has the lowest fixed costs. Furthermore the big-store owner has no pre-emption incentive to also instal $B 1$ at $L$, because there is no threat of competition from a no-anchor mall. If $\Gamma\left(L_{0}\left(M_{0 A}\right)\right)>0$ then $E$ has the upper hand in contracting and the equilibrium outcome must involve some stores entering at the mall. Either agreement is reached on the installation of one of the big stores there, or $E$ reverts to its disagreement option, a no-anchor mall. This does not mean that the mall is necessarily active in equilibrium, because one of the three possible equilibria is the configuration $\left(A_{2}, L_{1}(0)\right)$, in which all customers go to $A$, although $B 1$ still enters at $L$.

The purpose of $B 1$ 's entry in this latter configuration is to enable $E$ to commit contractually not to steal $A_{2}$ 's business by reverting to a no-anchor mall. In other words it provides a means for the contracting parties to ameliorate the problem of externalities on non-traders referred to in section 3 . If $G_{2}$ is substantially less than $K_{B 2}$ and if $\Gamma\left(L_{2}(0)\right)>\Gamma\left(L_{0}\left(M_{0 A}\right)\right)$ then there are efficiency gains to be had from operating the best big store at the stand-alone location. With no big-store merger there is no means for the mall owner to contractually share in these efficiency gains, because it cannot sign contracts over mall configurations with non-tenants. ${ }^{23}$ Thus if $\Gamma\left(L_{0}\left(M_{0 A}\right)\right)>0$ then the mall owner previously would have had no option but to force $B 2$ into the mall, thereby voiding some of the aforementioned efficiency gains. A big-store merger essentially allows $B$ to use $B 1$ 's mall tenancy to pay $E$ not to threaten its business at $A_{2}$ with a no-anchor mall. This outcome will be optimal for both parties if the necessary fixed costs, $G_{2}+K_{B 1}$, fall short of the fixed costs $K_{B 2}$ of installing $B 2$ at the mall, and if the joint net profits exceed $E$ 's net profits from the no-anchor mall. Clearly a necessary condition for this is that $G_{2}$ and $K_{B 1}$ both be strictly less than $K_{B 2} \cdot{ }^{24}$

It will be apparent from comparison of Proposition 7 and Proposition 2 that another effect of the merger is to eliminate the distortions in contracting outcomes arising from inefficient allocations of commitment power. We previously saw such distortions when $B 1$ had the power to commit to bargaining before $B 2$. This could result in $B 1$ being active at the mall in equilibrium, even though $B 2$ would have provided the mall with higher joint

\footnotetext{
${ }^{23}$ Insofar as they involve collusion between businesses at different locations such contracts might violate antitrust laws.

${ }^{24}$ Note that if $b_{1}>b_{2}$ then $K_{B 1}<K_{B 2}$ is not necessarily inconsistent with Assumption 4 .
} 
net profits. When both big stores are operated by the same company such conflicts can of course never arise, as it is always in the company's interests to ensure that consumers go to its most efficient retail operation. Accordingly Proposition 7 indicates that after a merger the less-efficient big store is never active in equilibrium (although it may be present as a 'dummy' place-holder at the mall).

When $D$ beats $A_{2}$ the post-merger equilibrium outcomes are the same as those that obtained before the merger with $B 2$ bargaining first. That is, if equation (4) holds, the outcome is the downtown location; otherwise the outcome is $L_{2}\left(M_{2 D}\right)$ or $L_{0}\left(N_{D}\right)$, depending on which is the greater of $\Gamma\left(L_{2}\left(M_{2 D}\right)\right)$ and $\Gamma\left(L_{0}\left(N_{D}\right)\right)$. Note that in this case there is no reason for the contracting parties to tenant the mall with dummy big stores, as an active mall is their only means of beating the downtown location.

The efficiency gains discussed above translate into gains in social welfare. Furthermore the big stores benefit from the merger (in the sense of increasing their combined profits), as long as their bargaining power does not decrease with the change in ownership. That is, let $1-\theta$ denote $B$ 's share (postmerger) of any surplus from contracting with the mall owner. Then we have the following result:

Proposition 8 Regardless of the order in which E bargains with the big stores beforehand,

a. social welfare is weakly improved by a merger between the two big stores;

b. if $1-\theta \geq \max \left(1-\theta_{1}, 1-\theta_{2}\right)$ then total profits of the big stores are weakly increased by the merger.

To see the intuition of part (a), note that prices after a big-store merger are no greater than before - they are either equal to $p_{2}(0)$ (if $A_{2} \succ D$ ), or $p_{0}\left(N_{D}\right)$ (if $D \succ A_{2}$ ), both before and after. The proof therefore focuses on the merger's effects on variable profits net of fixed costs. These are weakly increased because the merger counters the two types of contracting inefficiency mentioned above. That is, the merger first eliminates cases in which $E$ is forced, by reason of $B 1$ 's commitment to bargaining early, to accept this inefficient operator as the active big store in the mall. This type of inefficiency disappears entirely after the merger. In fact when $D \succ A_{2}$ the merger will have no effect on outcomes other than to remove this inefficiency. So the proposition certainly holds in this case.

When $A_{2} \succ D$ the merged big stores are also less vulnerable to the externalities-on-non-traders problem. This is for two reasons. First, since 
$B 1$ is now merged with $B 2$ the mall owner can no longer use contracting with $B 1$ as a threat against $B 2$. That is, the merger eliminates some previous cases where $B 2$ joined the mall not for cost reasons, but solely because $E$ threatened to otherwise revert to $L_{1}\left(M_{1 A}\right)$. Second, as discussed above the merger may lead to the mall owner accepting $B 1$ as a dummy mall tenant, allowing $E$ to receive some compensation in exchange for a commitment not to steal business from an efficient stand-alone big store. The two parties will only agree on this arrangement if it provides higher joint net profits than any alternative mall configuration (one of which would have been the outcome if there had been no merger). Thus joint net profits can again only be increased by the merger.

Note that the externalities-on-non-traders problem is not entirely eliminated by the merger. If, for example, $K_{B 1} \geq K_{B 2}$ then $B$ and $E$ would never agree on the $\left(A_{2}, L_{1}(0)\right)$ configuration, as it is too expensive in terms of fixed costs relative to $\left(A_{0}, L_{2}(0)\right)$. Then if $\Gamma\left(L_{0}\left(M_{0 A}\right)\right)>0$ the mall owner can still force $B 2$ into the mall by threatening to revert to a no-anchor mall. This is socially inefficient if $B 2$ 's fixed costs at the mall, $K_{B 2}$, are greater than those at $A$.

With respect to part (b) of the proposition, the increase in the big store's total payoffs is seen to depend on the merged entity getting no less a share of surplus than the big store with the most bargaining power pre-merger. Then total payoffs to the combined stores rise, firstly because they share in the efficiency gains noted above, and secondly because their post-merger disagreement payoffs can only improve with the merger, while those of the mall owner can only decline. (For example, $E$ can no longer threaten to revert to $L_{1}\left(M_{1 A}\right)$ when negotiating with $\left.B\right)$. The overall effects of the merger on the mall owner's payoffs are ambiguous. Payoffs may rise if the merger allows $E$ to share in the efficiency gains. Or they may fall, as for example when $G_{2}<K_{B 2}$ and $\Gamma\left(L_{1}\left(M_{1 A}\right)\right)>0>\Gamma\left(L_{0}\left(M_{0 A}\right)\right)$, in which case the merger induces $B$ to shift $B 2$ out of the mall to the stand-alone location, leaving $E$ with no tenants at all.

\section{Conclusion}

Although our framework is somewhat stylized, we believe that our three representative policy experiments illustrate effects on welfare and competitive outcomes which would still be present in a more general model. Two of the policies - a ban on stand-alone locations and a downtown subsidy

- might be viewed as alternative instruments for policymakers trying (for 
whatever reasons) to counter the dominance of malls and stand-alone 'bigbox' stores. While each of these two policies may have a net negative or positive welfare effect, their impacts will differ according to the particular circumstances of the market. We showed that the ban could increase welfare in two ways. First it may alleviate a problem of excess entry, leading to the replacement of a big store with a group of smaller stores with lower aggregate fixed costs. By way of contrast a subsidy for the downtown location tends only to encourage more entry at the mall. This may nevertheless be welfare improving if the amount of entry at the mall is insufficient, rather than excessive, because of the mall owner's monopolistic pricing incentives.

A second source of welfare gains from a location ban concerns the shift in the disagreement payoffs of parties negotiating for mall slots. Since the mall owner's bargaining position versus a low-cost big store is relatively strengthened by the ban, it could lead to this store replacing an inefficient rival as the mall anchor. This possibility arises in cases where the latter store is able to commit to first position in the bargaining sequence. While the technology to achieve this commitment is not explicitly modelled here, the general point is that a complete policy analysis needs to take into account effects on inefficiencies in the contracting for mall slots. It would be of interest to delve into the commitment issue more deeply, by, for example developing a two-period model with sunk location costs, in which the inefficient big store becomes the incumbent anchor in the first period and is later confronted by the appearance of a more efficient rival.

If the relevant policy is a one-off measure affecting a single market, relocation into a mall could be a costly response for a big store accustomed to locating mainly at stand-alone sites. A store may prefer to desert the market entirely. In terms of the parameters in our model this would be reflected in a relatively high value for the store's fixed costs at the mall, $K_{B 2}$. Insofar as some of our observations depend on relocation actually being feasible, our analysis could be interpreted more broadly as illustrating a firm's incentives if particular policies were to become widespread, affecting the firm's stores in many markets simultaneously. The wider the impact of the policy, the greater is the firm's incentive to consider negotiating with developers for slots in existing shopping malls. ${ }^{25}$

Inefficiencies in the contracting for mall slots could also be ameliorated

\footnotetext{
${ }^{25} \mathrm{~A}$ recent example from New York City shows that when retail space is scarce a big store will consider deviating from standard location plans. For its first store in that market Walmart initially considered occupying one floor of a multi-storey retail complex, an unusual departure from its typical store plans in markets elsewhere in the United States. See Greenhouse (2005).
} 
by our third policy experiment - a merger between two large stores. A merger of course eliminates the aforementioned problem of an inefficient bargaining sequence, since it puts both big stores under common ownership. It also alleviates the problem of externalities on non-traders. That is, it will sometimes result in the efficient big store moving from the mall to a less costly stand-alone location. One interesting instance of this latter effect is when the departing big store leaves its less-efficient sister store in the mall as a 'place-holder', to deter entry by other potential entrants, and to compensate the mall owner for the loss of a valuable tenant. In this respect it will be of interest to see whether or not the pending Sears-Kmart merger eventually leads to the closure of many Sears mall stores. Our analysis suggests strategic reasons to keep these stores, even if their revenues do not cover operating costs.

Work on extending the model could focus firstly on introducing differentiation between locations, thus allowing multiple sites to be simultaneously active. One question of interest is then whether a ban on stand-alone locations could actually lead to lower equilibrium prices, because of the creation of 'super malls', with more efficient anchor stores. Another approach might be to endogenize the cost differences between big stores, by allowing ex ante investments in cost reduction by the stores and the mall owner. As in Grossman and Hart (1986), the introduction of such investments naturally leads to consideration of the efficient ex post allocation of property rights. Gould, Pashigian, and Prendergast (2002) report that in fact many anchor stores in shopping malls own their premises - the interaction between the contracting problem, the own/lease decision, and the competition between locations would make an interesting topic for further study.

\section{Appendix}

Proof of Proposition 1: To see (a), note that if (3) holds then in the negotiation between $E$ and $B 2$ we have

$$
\begin{aligned}
\Delta_{2}^{B 2} & =V_{2}(0)-G_{2} \\
\Delta_{2}^{E} & =0
\end{aligned}
$$

Thus $\Delta_{2}^{E}+\Delta_{2}^{B 2}=V_{2}(0)-G_{2}$. Furthermore if $E$ and $B 2$ agree it will be on $M_{2}^{*}=0$. (Zero small firms at $L_{2}$ will yield a price there of $p_{2}(0)$, i.e., the same price as at $A_{2}$. Hence $M=0$ maximizes $\Gamma\left(L_{2}(M)\right)$ subject to the need to beat $D$.) Therefore $S_{2}^{*}=\Gamma\left(L_{2}(0)\right)-\left(\Delta_{2}^{E}+\Delta_{2}^{B 2}\right)=G_{2}-K_{B 2}$, and the result in (a) follows from Assumption 5. 
If (3) does not hold then $E$ can form a configuration to beat $A_{2}$ after disagreeing with $B 2$. The sum of $E$ and $B 2$ 's disagreement payoffs is then no greater than $\max \left\{\Gamma\left(L_{1}\left(M_{1 A}\right)\right), \Gamma\left(L_{0}\left(M_{0 A}\right)\right)\right\}$. If $\Gamma\left(L_{2}(0)\right)>\Gamma\left(L_{0}\left(M_{0 A}\right)\right)$ then $\Gamma\left(L_{2}(0)\right)>\max \left\{\Gamma\left(L_{1}\left(M_{1 A}\right)\right), \Gamma\left(L_{0}\left(M_{0 A}\right)\right)\right\}$ (using Assumption 4) and so $S_{2}\left(M_{2}^{*}=0\right)>0$, implying agreement on $L_{2}(0)$ (using Assumption 5). If $\Gamma\left(L_{2}(0)\right)<\Gamma\left(L_{0}\left(M_{0 A}\right)\right)$ then also $\Gamma\left(L_{1}\left(M_{1 A}\right)\right)<\Gamma\left(L_{0}\left(M_{0 A}\right)\right)$ (using Assumption 4$)$. Then in both the bargaining with $B 1$ and $B 2$ the disagreement payoffs are $\Delta_{1}^{E}+\Delta_{1}^{B 1}=\Delta_{2}^{E}+\Delta_{2}^{B 2}=\Gamma\left(L_{0}\left(M_{0 A}\right)\right)$ and thus $S_{1}^{*}<0$ and $S_{2}^{*}<0$. It follows that the outcome will then be $\Gamma\left(L_{0}\left(M_{0 A}\right)\right)$.

Proof of Proposition 2: Part (a) follows from the discussion of Proposition 1 . To see (b), note that $E$ 's disagreement payoff in negotiations with $B 1$ is at least $\Gamma\left(L_{0}\left(M_{0 A}\right)\right.$ ) (since this is a lower bound on his payoff from negotiations with $B 2)$. The joint net profits from agreement with $B 1$ cannot exceed $\Gamma\left(L_{1}\left(M_{1 A}\right)\right)$. Thus if $\Gamma\left(L_{0}\left(M_{0 A}\right)\right)>\Gamma\left(L_{1}\left(M_{1 A}\right)\right)$ agreement will not be reached with $B 1$ : what remains is a choice between $\Gamma\left(L_{2}(0)\right)$ and $\Gamma\left(L_{0}\left(M_{0 A}\right)\right)$, as in the discussion of Proposition 1 (b).

To see (c), suppose firstly that $\Gamma\left(L_{0}\left(M_{0 A}\right)\right)>0$; then if $E$ disagrees with $B 1$ and proceeds to bargaining with $B 2$ the disagreement payoffs there would be $\Delta_{2}^{B 2}+\Delta_{2}^{E}=0+\Gamma\left(L_{0}\left(M_{0 A}\right)\right)$ (since $E$ can beat $A_{2}$ with $L_{0}\left(M_{0 A}\right)$ ). The joint surplus in bargaining between $E$ and $B_{2}$ would therefore be $S_{2}^{*}=\Gamma\left(L_{2}(0)\right)-\Gamma\left(L_{0}\left(M_{0 A}\right)\right)$, which is positive because of Assumption 4 and because $\Gamma\left(L_{1}\left(M_{1 A}\right)\right)>\Gamma\left(L_{0}\left(M_{0 A}\right)\right)$. Then $E$ 's payoff in the event of disagreement with $B 1$ is $\Gamma\left(L_{0}\left(M_{0 A}\right)\right)+\theta_{2} S_{2}^{*}$. And $B 1$ 's disagreement payoff is 0 . The joint surplus from bargaining between $E$ and $B 1$ is then

$$
S_{1}^{*}=\Gamma\left(L_{1}\left(M_{1 A}\right)\right)-\left[\Gamma\left(L_{0}\left(M_{0 A}\right)\right)+\theta_{2} S_{2}^{*}\right],
$$

which is in this case equivalent to (5). If $S_{1}^{*}$ is positive (when $\theta_{2}=0$, for example) then the outcome will be $L_{1}\left(M_{1 A}\right)$. If it is negative (as when $\left.\theta_{2}=1\right)$ the outcome will be $L_{2}(0)$.

In the case of $\Gamma\left(L_{0}\left(M_{0 A}\right)\right)<0$ the preceding argument needs to be modified to allow for the change in $S_{2}^{*}$. Then $S_{2}^{*}=G_{2}-K_{B 2}$, so that $E$ 's payoff from disagreeing with $B 1$ is $\theta_{2} \max \left[0, S_{2}^{*}\right]$. (If $S_{2}^{*}<0$ then $E$ and $B 2$ would not agree and $E$ would get nothing.) Hence

$$
S_{1}^{*}=\Gamma\left(L_{1}\left(M_{1 A}\right)\right)-\theta_{2} \max \left[0, S_{2}^{*}\right],
$$

which is again seen to be consistent with (5). This joint surplus could be positive (if, e.g., $\theta_{2}=0$ ), leading to outcome $L_{1}\left(M_{1 A}\right)$, or it could be negative (if $G_{2}>K_{B 2}$ and $\Gamma\left(L_{1}\left(M_{1 A}\right)\right.$ ) is near 0 ), leading to outcome $L_{2}(0)$. 
Proof of Lemma 1: Differentiate (6) w.r.t. $M$, noting that

$$
\frac{d \pi_{B 2}}{d M}=\left(p-b_{2}\right) \frac{d q_{B 2}}{d M}+q_{B 2} p^{\prime} \cdot\left(\frac{d q_{B 2}}{d M}+M \frac{d q_{S 2}}{d M}+q_{S 2}\right)
$$

and

$$
\frac{d \pi_{S 2}}{d M}=(p-c) \frac{d q_{S 2}}{d M}+q_{S 2} p^{\prime} \cdot\left(\frac{d q_{B 2}}{d M}+M \frac{d q_{S 2}}{d M}+q_{S 2}\right),
$$

where $q_{B 2}$ and $q_{S 2}$ are respectively the per-firm outputs of the large and small firms in Cournot equilibrium. We arrive at the following expression, corresponding to a similar expression in Proposition 1 of Mankiw and Whinston (1986):

$$
\frac{d W}{d M}=\left(p-b_{2}\right) \frac{d q_{B 2}}{d M}+M(p-c) \frac{d q_{S 2}}{d M}+q_{S 2}(p-c)-K_{S} .
$$

(a) If $K_{S}=0$ and $b_{2}=c$ then (12) becomes

$$
(p-c)\left(\frac{d q_{B 2}}{d M}+M \frac{d q_{S 2}}{d M}+q_{S 2}\right) \text {. }
$$

The second bracketed term represents the response of equilibrium aggregate quantity to an increase in $M$. Under Cournot competition this is strictly positive, and also $p(M)-c>0$ for all $M<\infty$. (b) Under Assumption 2 we have $d q_{B 2} / d M<0, d q_{S 2} / d M<0$, and under Cournot competition (with $M<\infty$ ) we have $p(M)>c \geq b_{2}$. Thus if $q_{S 2}(p-c) \leq K_{S}$ we get $d W / d M<0$.

Proof of Proposition 4: The proof of (a) follows from the discussion in the text. To see (b) note that replacement of the less-efficient anchor would mean that the equilibrium outcome was switched from $\Gamma\left(L_{1}\left(M_{1 A}\right)\right)$ to $\Gamma\left(L_{2}(0)\right)$. Then prices and consumer welfare are not affected by the change. The (post-ban) disagreement payoffs in the bargaining between $E$ and $B 1$ cannot exceed $\Gamma\left(L_{2}(0)\right.$ ) (for $E$ ) plus 0 (for $B 1$ ). Hence a switch from $L_{1}\left(M_{1 A}\right)$ to $L_{2}(0)$ implies that $\Gamma\left(L_{1}\left(M_{1 D}\right)\right)<\Gamma\left(L_{2}(0)\right)$ (otherwise we have $S_{1}^{*}>0$, implying that agreement on $L_{2}(0)$ is not optimal). In turn this implies $\Gamma\left(L_{1}\left(M_{1 A}\right)\right)<\Gamma\left(L_{2}(0)\right)$, meaning that profits net of fixed costs increase, implying an overall increase in social welfare.

Proof of Proposition 5: Necessary conditions for the equilibrium outcome $A_{2}$ include $\Gamma\left(L_{0}\left(M_{0 A}\right)\right) \leq 0$ (see Proposition 1) and $A_{2} \succeq D$. Let $\bar{t}$ be the amount of subsidy that would produce just enough small firms 
at $D$ to match the price at $A_{2}: p_{0}\left(N_{D}(\bar{t})\right)=p_{2}(0)$. If a subsidy $t$ is less than or equal to $\bar{t}$ it has no effect on the equilibrium outcome $A_{2}$ or on the level of social welfare. So consider levels of subsidy $t>\bar{t}$, i.e., such that $p_{0}\left(N_{D}(t)\right)<p_{2}(0)$. We must then have $M_{0 D}(t)>M_{0 A}$, hence $\Gamma\left(L_{0}\left(M_{0 D}(t)\right)\right)<\Gamma\left(L_{0}\left(M_{0 A}\right)\right) \leq 0$, implying that $L_{0}$ cannot be an equilibrium outcome after the subsidy. Instead the outcome must be $L_{2}\left(M_{2 D}\right)$ or $D$.

Decompose the welfare effects of the subsidy into

$$
W(t)-W(0)=W(t)-W(\bar{t})+W(\bar{t})-W(0)=W(t)-W(\bar{t}) .
$$

And suppose firstly that the post-subsidy outcome is $L_{2}\left(M_{2 D}(t)\right)$. Then social welfare after a subsidy of $t$ is:

$W(t)=\int_{p_{2}\left(M_{2 D}(t)\right)}^{\infty} q(u) \cdot d u+\pi_{B 2}\left(M_{2 D}(t)\right)+M_{2 D}(t) \pi_{S 2}\left(M_{2 D}(t)\right)-K_{B 2}-M_{2 D}(t) K_{S}$.

Also,

$$
W(\bar{t})=\int_{p_{2}(0)}^{\infty} q(u) \cdot d u+V_{2}(0)-G_{2} \geq \int_{p_{2}(0)}^{\infty} q(u) \cdot d u+V_{2}(0)-K_{B 2} .
$$

Hence

$$
\begin{aligned}
& W(t)-W(\bar{t}) \leq \int_{p_{2}\left(M_{2 D}(t)\right)}^{p_{2}(0)} q(u) \cdot d u+V_{2}\left(M_{2 D}(t)\right)-V_{2}(0)-M_{2 D}(t) K_{S} \\
& \text { i.e., } \quad W(t)-W(\bar{t}) \leq \\
& \qquad \int_{p_{2}\left(M_{2 D}(t)\right)}^{p_{2}(0)} q(u) \cdot d u+\pi_{B 2}\left(M_{2 D}(t)\right)-\pi_{B 2}(0)+M_{2 D}(t)\left[\pi_{S 2}\left(M_{2 D}(t)\right)-K_{S}\right]
\end{aligned}
$$

The effect of increases in $t$ above $\bar{t}$ is to raise $M_{2 D}$, the number of small firms needed at $L_{2}$ to match the downtown price. Also $M_{2 D}(\bar{t})=0$, by the definition of $\bar{t}$. Hence if $t \geq \bar{t}, \pi_{S 2}\left(M_{2 D}(t)\right) \leq \pi_{S 2}(0)$, where $\pi_{S 2}(0)$ was defined as $\lim _{M \rightarrow 0} \pi_{S 2}(M)$. Alternatively, since $p_{2}(0)=p_{0}\left(M_{0 A}\right)$ by the definition of $M_{0 A}$, we have $\pi_{S 2}(0)=\pi_{S 0}\left(M_{0 A}\right)$ from Lemma 2. Since $\Gamma\left(L_{0}\left(M_{0 A}\right)\right) \leq 0$ was necessary for $A_{2}$ to be the original equilibrium outcome, we have $\pi_{S 2}\left(M_{2 D}(t)\right) \leq \pi_{S 0}\left(M_{0 A}\right) \leq K_{S}$. The conclusion of the Proposition then follows from applying Lemma 1 (b) to equation (13).

Alternatively, suppose that the post-subsidy outcome was $D(t)$. The number of active small firms in this outcome, $N_{D}(t)$, must exceed $N_{D}(t=0)$, 
the number consistent with (unsubsidized) free entry at $D$ (if that were the only permitted location). Social welfare at this outcome can be written as:

$$
W(t)=\int_{p_{0}\left(N_{D}(t)\right)}^{\infty} q(u) \cdot d u+N_{D}(t) \pi_{S 0}\left(N_{D}(t)\right)-N_{D}(t)\left(K_{D}-t\right)-t N_{D}(t) .
$$

It then follows from, e.g., Lemma 1 (b) that

$$
W(t)<\int_{p_{0}\left(N_{D}(t=0)\right)}^{\infty} q(u) \cdot d u .
$$

and the RHS of this expression is in turn no greater than

$$
\int_{p_{2}(0)}^{\infty} q(u) \cdot d u+V_{2}(0)-G_{2}
$$

since $p_{2}(0) \leq p_{0}\left(N_{D}(t=0)\right)$ and $V_{2}(0) \geq G_{2}$. Hence the move from $A_{2}$ to $D(t)$ reduces social welfare overall.

Proof of Lemma 3: Start by noting the following two identities, the second of which follows from Lemma 2:

$$
\pi_{S 0}\left(N_{D}\right) \equiv K_{D}, \pi_{S 2}\left(M_{2 D}\right) \equiv K_{D}
$$

Totally differentiate each of these w.r.t. $K_{D}$, and then apply the small firms' FONC in each case, to arrive at:

$$
\begin{aligned}
\left(N_{D}-1\right) \frac{d q_{S 0}}{d K_{D}}+q_{S 0} \frac{d N_{D}}{d K_{D}} & =\frac{1}{q_{S 0} p^{\prime}}, \text { and } \\
\frac{d q_{B 2}}{d K_{D}}+\left(M_{2 D}-1\right) \frac{d q_{S 2}}{d K_{D}}+q_{S 2} \frac{d M_{2 D}}{d K_{D}} & =\frac{1}{q_{S 2} p^{\prime}} .
\end{aligned}
$$

Here $q_{S 0}$ (resp. $q_{S 2}$ ) represents the quantity sold by each small firm in symmetric (resp. asymmetric) Cournot equilibrium. (Similarly for $q_{B 2}$, for the big firm.)

Using the identities in (14), and the definitions of $V_{0}($.$) and V_{2}($.$) , equa-$ tion (11) can be rewritten as:

$$
Y=\pi_{B 2}\left(M_{2 D}\right)+\left(M_{2 D}-N_{D}\right)\left(K_{D}-K_{S}\right)-K_{B 2}
$$

Then

$$
\frac{d Y}{d K_{D}}=\frac{d}{d K_{D}}\left[\pi_{B 2}\left(M_{2 D}\right)\right]+\left(M_{2 D}-N_{D}\right)+\left(K_{D}-K_{S}\right)\left(\frac{d M_{2 D}}{d K_{D}}-\frac{d N_{D}}{d K_{D}}\right) .
$$


Take the FONC's for $q_{B 2}$ and $q_{S 0}$ :

$$
\begin{aligned}
\left(p-b_{2}\right)+q_{B 2} p^{\prime} & =0 \\
(p-c)+q_{S 0} p^{\prime} & =0 .
\end{aligned}
$$

Totally differentiate (20) w.r.t. $K_{D}$, re-arrange, apply (15), and re-arrange again to arrive at:

$$
\frac{d q_{S 0}}{d K_{D}}=\frac{-\left(p^{\prime}+q_{S 0} p^{\prime \prime}\right)}{q_{S 0} p^{\prime}\left(2 p^{\prime}+q_{S 0} p^{\prime \prime}\right)} .
$$

It follows then from Assumption 2 that $d q_{S 0} / d K_{D}>0$, and note that by virtue of Lemma $2, d q_{S 2}\left(M_{2 D}\right) / d K_{D} \equiv d q_{S 0}\left(N_{D}\right) / d K_{D}$. Substitute $(21)$ into the total derivative of (20), and re-arrange to arrive at:

$$
\frac{d N_{D}}{d K_{D}}=\frac{N_{D} q_{S 0} p^{\prime \prime}+\left(N_{D}+1\right) p^{\prime}}{q_{S 0}^{2} p^{\prime}\left(2 p^{\prime}+q_{S 0} p^{\prime \prime}\right)} .
$$

By a similar process of total differentiation, starting from (19), and application of (16), it is possible to arrive at:

$$
\frac{d M_{2 D}}{d K_{D}}=\frac{M_{2 D}\left(p^{\prime}+q_{S 0} p^{\prime \prime}\right)+2 p^{\prime}+q_{B 2} p^{\prime \prime}}{q_{S 2}^{2} p^{\prime}\left(2 p^{\prime}+q_{S 2} p^{\prime \prime}\right)} .
$$

Combining (22) and (23), it can be seen that

$$
\frac{d M_{2 D}}{d K_{D}}-\frac{d N_{D}}{d K_{D}} \geq 0
$$

implying that the third term on the RHS of (18) is non-negative (given $K_{S} \leq K_{D}$, as supposed in the lemma). Consider then the first term on the RHS in (18). By taking that derivative w.r.t. $K_{D}$, using the large firm's FONC and some of the other expressions derived above we arrive at:

$$
\frac{d}{d K_{D}}\left[\pi_{B 2}\left(M_{2 D}\right)\right]=\left(N_{D}-M_{2 D}\right) \frac{2 p^{\prime}+q_{B 2} p^{\prime \prime}}{2 p^{\prime}+q_{S 0} p^{\prime \prime}},
$$

which implies that

$$
\frac{d}{d K_{D}}\left[\pi_{B 2}\left(M_{2 D}\right)\right]>N_{D}-M_{2 D} \Leftrightarrow p^{\prime \prime}<0 .
$$

The required conclusions then follow from examination of (18).

Proof of Proposition 6: (Sketch) (a) The core of this result is encapsulated in Lemma 3. To complete the proof it is necessary to go into tedious 
detail to rule out some other trivial cases (e.g., the subsidy cannot switch $D$ or $L_{0}$ to $A_{2}$, etc.), which we omit. Full details are available from the authors.

(b) Given concave demand, it follows from part (a) that if the big store was not active before the subsidy then nor will it be active afterwards. Suppose then that the pre-subsidy outcome was $A_{2}$, implying that $G_{2} \leq$ $K_{B 2}$, that $A_{2} \succeq D(t=0)$, and that $B 2$ gets $\Gamma\left(A_{2}(0)\right)$. If $A_{2} \succeq D(t)$ after the subsidy then there is no change in any payoffs; if $D(t) \succ A_{2}$ then the post-subsidy outcome could be $D, L_{0}$, or $L_{2}\left(M_{2 D}\right)$. If $D$ or $L_{0}, B 2$ 's payoffs are reduced to zero; if $L_{2}\left(M_{2 D}\right)$ then $B 2$ now gets a partial share of the joint profits $\Gamma\left(L_{2}\left(M_{2 D}\right)\right)$, which are strictly less than $\Gamma\left(A_{2}(0)\right)$, since $V_{2}\left(M_{2 D}(t)\right)<V_{2}(0)$ and $G_{2} \leq K_{B 2}$.

Or suppose the pre-subsidy outcome was $L_{2}\left(M_{2 D}\right)$, where $M_{2 D}=0$ if $A_{2} \succeq D$. The post-subsidy outcome must be $L_{2}\left(M_{2 D}(t)\right), L_{0}$, or $D$. If one of the latter two, B2's payoffs are reduced to 0 . If the former, the joint net profits are $\Gamma\left(L_{2}\left(M_{2 D}(t)\right)\right)$, which are smaller than the original joint net profits $\Gamma\left(L_{2}\left(M_{2 D}(t=0)\right)\right)$, since $M_{2 D}$ is increasing in $t$. To complete the proof it is then necessary to show that the subsidy cannot increase the fraction of these joint net profits which go to $B 2$. This requires an explanation of the effect of the subsidy on the disagreement payoffs which we omit for reasons of space. It is easy to see that the subsidy cannot increase B2's disagreement payoffs; to show that it can only increase the share of joint net profits going to $E$ requires a long derivation of an analogue to Lemma 3 for the difference $\Gamma\left(L_{2}\left(M_{2 D}\right)\right)-\Gamma\left(L_{1}\left(M_{1 D}\right)\right)$.

Proof of Proposition 7: (a) If $\Gamma\left(L_{0}\left(M_{0 A}\right)\right)<0$ then $E$ cannot form a configuration to beat $A_{2}$ if he disagrees with $B$. Disagreement payoffs in the bargaining between $E$ and $B$ are therefore 0 and $V_{2}(0)-G_{2}$, respectively. They will not agree on $\left(A_{2}, L_{1}(0)\right)$ because that would imply a negative contracting surplus:

$$
S^{*}=V_{2}(0)-G_{2}-K_{B 1}-\left(V_{2}(0)-G_{2}\right)=-K_{B 1}<0 .
$$

Hence if agreement is reached it will be on $\left(A_{0}, L_{2}\left(M_{2 D}\right)\right)$, where $M_{2 D}=0$ here because $A_{2} \succ D$. Thus $S^{*}=G_{2}-K_{B 2}$ and the conclusion follows.

(b) If $\Gamma\left(L_{0}\left(M_{0 A}\right)\right)>0$ then $E$ can beat $A_{2}$ if he disagrees with $B$. The disagreement payoffs in the contracting between $E$ and $B$ are therefore $\Gamma\left(L_{0}\left(M_{0 A}\right)\right)$ and 0 , respectively. The surplus from agreeing on $\left(A_{0}, L_{2}(0)\right)$ is therefore $V_{2}(0)-K_{B 2}-\Gamma\left(L_{0}\left(M_{0 A}\right)\right)$, while the surplus from agreeing on $\left(A_{2}, L_{1}(0)\right)$ is $V_{2}(0)-G_{2}-K_{B 1}-\Gamma\left(L_{0}\left(M_{0 A}\right)\right)$. The conclusion follows. 
Proof of Proposition 8: (a) The post-merger equilibrium price is in all cases the same as the pre-merger price (regardless of the bargaining order). Therefore consumer welfare cannot be reduced by a merger. We will show that variable profits net of fixed costs are weakly increased by a merger.

Suppose that $A_{2}$ beats $D$. Referring to Propositions 1 and 2, note that if $\max \left(\Gamma\left(L_{1}\left(M_{1 A}\right)\right), \Gamma\left(L_{0}\left(M_{0 A}\right)\right)\right)<0$ then the equilibrium outcome is the same pre- and post-merger. If $\max \left(\Gamma\left(L_{1}\left(M_{1 A}\right)\right), \Gamma\left(L_{0}\left(M_{0 A}\right)\right)\right)>0$ then joint net profits before a merger are no greater than $\max \left(\Gamma\left(L_{2}(0)\right), \Gamma\left(L_{0}\left(M_{0 A}\right)\right)\right)$. (Note that, in the event that $B 1$ is active pre-merger, joint net profits are $\Gamma\left(L_{1}\left(M_{1 A}\right)\right)$, which is less than $\Gamma\left(L_{2}(0)\right)$ by Assumption 4.) After a merger joint net profits are either $\max \left(\Gamma\left(L_{2}(0)\right), \Gamma\left(L_{0}\left(M_{0 A}\right)\right), \Gamma\left(A_{2}, L_{1}(0)\right)\right.$ (if $\Gamma\left(L_{0}\left(M_{0 A}\right)\right)>0$ ) or $\max \left(V_{2}(0)-K_{B 2}, V_{2}(0)-G_{2}\right)\left(\right.$ if $\left.\Gamma\left(L_{0}\left(M_{0 A}\right)\right)<0\right)$. In either case they are weakly greater than pre-merger, and strictly greater if, e.g., $G_{2}<K_{B 2}$.

Or suppose that $D \succ A_{2}$. If $\max \left(\Gamma\left(L_{2}\left(M_{2 D}\right)\right), \Gamma\left(L_{0}\left(N_{D}\right)\right)\right)<0$ then the equilibrium outcome is $D$ before and after the merger. If $\max \left(\Gamma\left(L_{2}\left(M_{2 D}\right)\right)\right.$, $\left.\Gamma\left(L_{0}\left(N_{D}\right)\right)\right)>0$ then joint net profits before the merger are no greater than $\left.\max \left(\Gamma\left(L_{2}\left(M_{2 D}\right)\right), \Gamma\left(L_{0}\left(N_{D}\right)\right)\right)\right)$, whereas they will be exactly equal to this quantity after the merger. (Note again that if $B 1$ is active pre-merger, joint net profits are $\Gamma\left(L_{1}\left(M_{1 D}\right)\right) \leq \Gamma\left(L_{2}\left(M_{2 D}\right)\right)$.)

(b) Prior to the merger at most one big store makes positive profits in equilibrium. Furthermore it can be seen that if a big store was active in equilibrium before the merger then a big store (possibly a different one) will be active in equilibrium after the merger. (The proof is by contradiction and is omitted.) So there are no cases where big stores disappear from the equilibrium as a result of the merger. If $A_{2} \succeq D$ and $\Gamma\left(L_{0}\left(M_{0 A}\right)\right)<0$ then the disagreement payoff of any big store making positive profits prior to the merger is no greater than $V_{2}(0)-G_{2}$, which is exactly $B$ 's disagreement payoff after the merger. In any other case pre-merger disagreement payoffs for $B 1$ and $B 2$ are both 0 . So $B$ 's disagreement payoff is in all cases no less than the disagreement payoff of the active big store before the merger.

The mall owner's disagreement payoff after the merger is $\max \left(0, \Gamma\left(L_{0}\left(M_{0 A}\right)\right)\right)$ (or $\max \left(0, \Gamma\left(L_{0}\left(N_{D}\right)\right)\right.$ ), if $\left.D \succ A_{2}\right)$. Prior to the merger E's disagreement payoff in any bargaining with big stores would have been at least $\max \left(0, \Gamma\left(L_{0}\left(M_{0 A}\right)\right)\right)\left(\right.$ or $\max \left(0, \Gamma\left(L_{0}\left(N_{D}\right)\right)\right)$, if $\left.D \succ A_{2}\right)$. Hence $E$ 's disagreement payoffs are never increased by the merger.

We have seen in part (a) that joint net profits of the active configuration are in all cases weakly increased by the merger. In view of the effects on the disagreement payoffs, it follows that total payoffs of the big stores are not reduced by the merger, if $1-\theta \geq \max \left(1-\theta_{1}, 1-\theta_{2}\right)$. To see that they 
may be strictly increased, consider the case of $B 2$ bargaining first, $A_{2} \succ D$, $\Gamma\left(L_{1}\left(M_{1 A}\right)\right)>0>\Gamma\left(L_{0}\left(M_{0 A}\right)\right), G_{2}<K_{B 2}$. Prior to the merger, $B 1$ gets 0 and $B 2$ gets $\left(1-\theta_{2}\right)\left[\Gamma\left(L_{2}(0)\right)-\theta_{1} \Gamma\left(L_{1}\left(M_{1 A}\right)\right)\right]$. After the merger $B$ gets $V_{2}(0)-G_{2}$, which is a strict improvement. 


\section{References}

Armstrong, Mark (2004), 'Competition in two-sided markets', mimeo., University College London.

Basker, Emek (2005), 'Selling a cheaper mousetrap: Wal-Mart's effect on retail prices', University of Missouri Dept. of Economics w.p.

Bhatnagar, Parija (2004), 'The Kmart-Sears deal', money.cnn.com, November 17 .

Dudey, M. (1990), 'Competition by choice: the effect of consumer search on firm location decisions', American Economic Review, 80, 1092-104.

Gehrig, T. (1998), 'Competing markets', European Economic Review, 42, 2, 277-310.

Gibson, Diane (2003), 'Neighborhood characteristics and the targeting of tax increment financing in Chicago', Journal of Urban Economics, 54, 309-27.

Gould, Eric, Peter Pashigian and Canice Prendergast (2002), 'Contracts, externalities, and incentives in shopping malls', mimeo., Hebrew University of Jerusalem.

Greenhouse, Steven (2005), 'Foes dig in as Wal-mart aims for city', New York Times, 10 February.

Grossman, Sanford, and Oliver Hart (1986), 'The costs and benefits of ownership: A theory of vertical and lateral integration', Journal of Political Economy, 94, 4, 691-719.

Konishi, Hideo, and Michael Sandfort (2003), 'Anchor stores', Journal of Urban Economics, 53, 413-35.

Mankiw, G. N., \& M.D. Whinston (1986), 'Free entry and social inefficiency', RAND Journal of Economics, 17, 1, 48-58.

Nocke, Volker, Martin Peitz and Konrad Stahl (2004), 'Platform ownership', University of Pennsylvania PIER w.p. 04-029.

O'Keefe, Suzanne (2004), 'Job creation in California's enterprise zones: a comparison using a propensity score matching model', Journal of Urban Economics, 55, 131-50. 
Pashigian, Peter, and Eric Gould (1998), 'Internalizing externalities: The pricing of space in shopping malls', Journal of Law and Economics, 41, 1, $115-42$.

Pennsylvania Department of Community and Economic Development (2004), 'New communities: Program guidelines'.

Prentice, D., \& H. Sibly (1996), 'A search theoretic explanation of multioutlet retailers', Economic Record, 72, 359-69.

Rey, Patrick, and Jean Tirole (1996), 'A primer on vertical foreclosure', forthcoming in M. Armstrong and R. Porter (eds.), Handbook of Industrial Organization, Vol. 3, North-Holland.

Rochet, Jean-Charles, and Jean Tirole (2003), 'Platform competition in twosided markets', Journal of the European Economic Association, 1, 4, 9901029 .

Segal, Ilya (1999), 'Contracting with externalities', Quarterly Journal of Economics, 114, 2, 337-88.

Tirole, Jean (1988), The Theory of Industrial Organization, MIT Press, Cambridge, MA.

West, D.S. (1992), 'An empirical analysis of retail chains and shopping center similarity', Journal of Industrial Economics, 40, 201-221. 